\title{
INVESTIGATING THE POTENTIAL ANTI-DIABETIC MECHANISMS OF WATER-SOLUBLE PALM FRUIT EXTRACT
}

\author{
SOON-SEN LEOW ${ }^{1 *}$; NORFAZLINA MOHD NAWI ${ }^{1,2}$; SYED FAIRUS ${ }^{1}$ \\ and RAVIGADEVI SAMBANTHAMURTHI ${ }^{1,3}$
}

\begin{abstract}
Water-Soluble Palm Fruit Extract (WSPFE) obtained from the aqueous vegetation liquor of oil palm (Elaeis guineensis) fruit milling demonstrated anti-diabetic effects in Nile rats, but the related mechanisms were unknown. Here, we investigated the potential effects of WSPFE samples on glucose uptake and enzymes involved in carbohydrate hydrolysis and incretin degradation. Glucose uptake assays were performed using spray dried (SD) WSPFE, freeze dried (FD) WSPFE, WSPFE ethyl acetate fraction (EAF) and seven individual WSPFE fractions obtained from WSPFE EAF on everted mouse intestinal sacs ex vivo and Caco-2 cell monolayers in vitro. $\alpha$-glucosidase, $\alpha$-amylase and dipeptidyl peptidase-4 (DPPIV) enzymatic assays were performed in vitro. Glucose uptake assays revealed that all the WSPFE samples tested did not inhibit glucose absorption. However, WSPFE EAF consistently had stronger inhibitory effects on $\alpha$-glucosidase, $\alpha$-amylase and DPPIV enzymes compared to SD WSPFE and FD WSPFE. SD WSPFE inhibited $\alpha$-amylase better than FD WSPFE. In terms of individual fractions, F2 demonstrated the strongest inhibitory effects against $\alpha$-glucosidase and DPPIV. Hence, al though WSPFE samples did not inhibit glucose uptake, they showed inhibitory effects on the three enzymes tested, especially WSPFE EAF and F2. Further studies to investigate their effects on carbohydrate digestion and postprandial hyperglycaemia are warranted.
\end{abstract}

Keywords: glucose, metabolic syndrome, oil palm phenolics.

Received: 2 July 2021; Accepted: 4 October 2021; Published online: 17 January 2022.

\section{INTRODUCTION}

Rising physical inactivity, obesity and consumption of energy-dense diets have resulted in an unprecedented increase in the incidence and prevalence of type 2 diabetes mellitus (T2DM),

1 Malaysian Palm Oil Board,

6 Persiaran Institusi, Bandar Baru Bangi,

43000 Kajang, Selangor, Malaysia.

2 University College London, 5, University Street London, WC1E 6JF, United Kingdom.

3 Academy of Sciences Malaysia, Level 20, West Wing, MATRADE Tower, Jalan Sultan Ahmad Shah, off Jalan Tuanku Abdul Halim, 50480 Kuala Lumpur, Malaysia.

* Corresponding author e-mail: ssleow@mpob.gov.my with a projected increase to 642 million cases by 2040 (Chatterjee et al., 2017). T2DM is characterised by insulin resistance, declining insulin production and pancreatic $\beta$-cell failure (Lyssenko et al., 2008). In overcoming T2DM, plant phenolic compounds may influence glucose metabolism via different mechanisms (Cuervo et al., 2014; Hanhineva et al., 2010; Moco et al., 2012). These include inhibition of intestinal carbohydrate digestion, inhibition of intestinal glucose absorption, stimulation of pancreatic insulin secretion, modulation of hepatic glucose release, as well as activation of insulin receptors and glucose uptake in insulin-sensitive tissues. Modulation of gut flora activities that effect changes in energy metabolism, as well as modulation of gene expression and intracellular signalling pathways may also occur. An important 
property of phenolic compounds identified is their preventive effects against long-term T2DM complications, such as retinopathy, nephropathy and neuropathy, which may help improve quality of life in diabetic patients (Bahadoran et al., 2013).

An extract obtained from the aqueous vegetation liquor produced from the milling of the oil palm (Elaeis guineensis) fruit, termed WaterSoluble Palm Fruit Extract (WSPFE), Palm Fruit Bioactives, palm fruit juice or oil palm phenolics (Sambanthamurthi et al., 2011a), is rich in phenolic acids, including three caffeoylshikimic acid isomers, p-hydroxybenzoic acid and protocatechuic acid (Sambanthamurthi et al., 2011a). It also contains an indoleacetic acid derivative (Sambanthamurthi et al., 2014) and shikimic acid (Sambandan et al., 2011). Pre-clinical in vitro, ex vivo and in vivo studies have shown that WSPFE has beneficial bioactive properties, while clinical studies in healthy volunteers have demonstrated that it is safe for human consumption and confers antioxidant as well as anti-inflammatory effects (Leow et al., 2021a). We previously showed that WSPFE blocked T2DM progressionin 12 week-old maleNilerats (Arvicanthis niloticus), with a significant decrease in blood glucose after 17 weeks of treatment (Sambanthamurthi et al., 2011b). We also demonstrated that WSPFE delayed T2DM onset, completely prevented it and even reversed advancing T2DM in Nile rats (Bolsinger et al., 2014). WSPFE thus, has excellent antidiabetic effects. It would therefore be important to identify the potential mechanisms involved and the components which confer these effects, if possible, via bioactivity-guided fractionation. The underlying mechanism is not likely a rise in insulin secretion, as insulin levels were not significantly increased after WSPFE supplementation in Nile rats (Bolsinger et al., 2014; Sambanthamurthi et al., 2011b). This necessitates investigations into other possible mechanisms, which may include inhibition of glucose absorption, carbohydrate hydrolysis or incretin degradation.

In addition, different drying methods may have effects on the biological activities of polyphenols. For example, higher chokeberry polyphenol levels were present after drying at high temperatures as compared to after freeze drying (Horszwald et al., 2013), while spray dried (SD) papaya products also retained higher levels of flavonoids and phenolic compounds as compared to freeze dried (FD) products (Gomes et al., 2018). As such, investigating different drying methods would also be important for preparation of related products with optimal biological activities.

When compared to other routes of exposure, the gastrointestinal tract is highly relevant to the effects of phenolic compounds, as the areas of exposure of the gastrointestinal tract to these ingested compounds are extensive. Ex vivo everted intestinal sacs have been used in various drug pharmacokinetic and pharmacodynamic studies (Alam et al., 2012). Caco-2 cell monolayers have also been used as an in vitro model of the intestinal barrier for studies on metabolism and transport kinetics of dietary phenolic compounds (Sambuy et al., 2005).

In humans, dietary glucose intake primarily comes from the hydrolysis of carbohydrates, such as starch. Salivary and pancreatic $\alpha$-amylases, as well as intestinal $\alpha$-glucosidases, are the carbohydratehydrolysing enzymes involved in the generation of dietary glucose. Inhibition of these carbohydratehydrolysing enzymes can be an important concept for T2DM management (Apostolidis and Lee, 2010; Striegel et al., 2015). In addition, the dipeptidyl peptidase-4 (DPPIV) enzyme is inyolved in the degradation of incretins, which are gut peptides that are secreted after nutrient intake and stimulate insulin secretion. Glucose-dependent insulinotropic polypeptide (GIP) and glucagon-like peptide-1 (GLP-1) are the known incretin hormones from the cells of the upper and lower gut, respectively. These two hormones are responsible for the incretin effect, a phenomenon where there is a two- to threefold higher insulin secretory response to oral as compared to intravenous glucose administration. In subjects with T2DM, this incretin effect is diminished or no longer present (Nauck and Meier, 2018). The inhibition of DPPIV is thus, another possible anti-diabetic mechanism (Fan et al., 2013).

In the present study, we were interested to find out the possible mechanisms by which WSPFE samples confer potential protection against T2DM. Thus, we sought to investigate whether they have inhibitory activities on glucose absorption, as well as their potential effects on enzymes involved in carbohydrate hydrolysis and incretin degradation. We compared the effects of WSPFE samples produced using two different drying methods and fractions prepared using preparative highperformance liquid chromatography (HPLC), so as to inform future studies on carbohydrate digestion and postprandial hyperglycaemia using WSPFE samples.

\section{MATERIALS AND METHODS}

\section{Preparation of Water-Soluble Palm Fruit Extract (WSPFE) Samples}

The solvents used were purchased from Merck KGaA (Darmstadt, Germany) unless otherwise stated. Liquid WSPFE was produced at the Malaysian Palm Oil Board (MPOB) Phenolic Antioxidant Pilot Plant as described by Sambanthamurthi et al. (2008) in Labu, Negeri Sembilan, Malaysia. Spray dried (SD) WSPFE 
was obtained through the spray drying process carried out on liquid WSPFE at Biotropics Malaysia Berhad, Shah Alam, Selangor, Malaysia. This spray drying process was performed using the Agridon AG-10 spray dryer (Agridon Technologies, Sungai Buloh, Selangor, Malaysia), with the following conditions: inlet temperature of $185^{\circ} \mathrm{C}-200^{\circ} \mathrm{C}$, outlet temperature of $110^{\circ} \mathrm{C}-130^{\circ} \mathrm{C}$, aspirator value

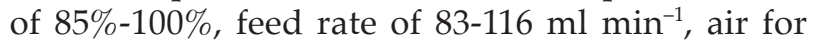
drying and compressed air with a flow of 150-200 $\mathrm{kPa}$ for pneumatic liquid atomiser. Freeze dried (FD) WSPFE was obtained by freeze drying liquid WSPFE at MPOB using a FreeZone 2.5 L Benchtop Freeze Dry System (Labconco Corp., Kansas City, Missouri, United States of America) at $-54^{\circ} \mathrm{C}$. WSPFE ethyl acetate fraction (EAF) was obtained by extracting liquid WSPFE with ethyl acetate using a sample:solvent ratio of $1: 3$ and then collecting the upper solvent layer for rotary evaporation and freeze drying. Compared to using other solvents such as hexane, chloroform, methanol and water, extraction using ethyl acetate has been previously found to result in plant extracts containing high total phenolic content (Ooi et al., 2016), as well as high carbohydrate-hydrolysing enzyme inhibitory activities (Ablat et al., 2017; Nguyen et al., 2020a) and anti-diabetic properties in animal models (Ablat et al., 2017; Nguyen et al., 2020b; Olatunji et al., 2017; Ooi et al., 2018).

Individual WSPFE fractions (F1-F7) were prepared by subjecting WSPFE EAF to preparative HPLC using a Waters Preparative AutoPurification HPLC System (Waters Corp., Milford, Massachusetts, United States of America) as described previously (Leow et al., 2021b). Separation was achieved by using a reverse phase Waters Atlantis C18 5 um column (Waters Corporation, Milford, Massachusetts, United States of America). A binary gradient system was used as the mobile phase, with phase A comprising $0.02 \%(\mathrm{v} / \mathrm{v})$ trifluoroacetic acid in distilled water and phase B comprising 70\%:30\% (v/v) methanolacetonitrile. A flow rate of $20 \mathrm{ml} \mathrm{min}$-1 and a pressure limit of $2.76 \times 10^{4} \mathrm{kPa}$ were used. The gradient elution with a total run time of $55 \mathrm{~min}$ was as follows: Started from $100 \%(\mathrm{v} / \mathrm{v})$ phase A and $0 \%(\mathrm{v} / \mathrm{v})$ phase $\mathrm{B}$, increased to $32.5 \%(\mathrm{v} / \mathrm{v})$ phase B over $40 \mathrm{~min}$, then increased to $62.5 \%(\mathrm{v} / \mathrm{v})$ phase B over $6 \mathrm{~min}$ and finally decreased to $0 \%$ $(\mathrm{v} / \mathrm{v})$ phase B over $9 \mathrm{~min}$. Seven fractions (F1F7) as characterised by ultraviolet/visible (UV/ VIS) detection at $280 \mathrm{~nm}$ UV wavelength were collected. The identities of the major components in these fractions were confirmed by the retention times and UV/VIS spectra of the peaks which had already been identified in WSPFE previously. The related preparative HPLC chromatogram of these prepared fractions had been published previously (Leow et al., 2021b).

\section{Glucose Uptake of Everted Mouse Intestinal Sacs}

Male, Institute of Cancer Research (ICR) mice aged between nine to 19 weeks ( 30 to $44 \mathrm{~g}$ ) obtained from the Laboratory Animal Resources Unit, Universiti Kebangsaan Malaysia (UKM), Kuala Lumpur, Malaysia were maintained in a controlled environment of $25^{\circ} \mathrm{C}$ with a 12-hr/12-hr light/dark cycle. Twelve hours prior to the preparation of the everted intestinal sacs, the mice were only given access to water but not food. These animals were then euthanised using the cervical dislocation technique. Everted mouse intestinal sacs were prepared according to adapted protocols (Hamilton and Butt, 2013; Mary and Rao, 2002), with the relevant animal care and use protocols approved by the UKM Animal Ethics Committee with the approval number MPOB/2016/LEOW/23-MAR./735-APR.2016-MAR.2019-AR-CAT2.

The chemicals used for glucose uptake experiments were purchased from Sigma-Aldrich (Saint Louis, Missouri, United States of America) unless otherwise stated. Ringer's solution was used as the buffer in the glucose uptake experiments on everted mouse intestinal sacs (Luz-Madrigal et al., 2015). This buffer consisted of $123 \mathrm{mM}$ sodium chloride $(\mathrm{NaCl}), 1.53 \mathrm{mM}$ calcium chloride $\left(\mathrm{CaCl}_{2}\right)$, $5 \mathrm{mM}$ potassium chloride $(\mathrm{KCl}), 0.8 \mathrm{mM}$ disodium hydrogen phosphate $\left(\mathrm{Na}_{2} \mathrm{HPO}_{4}\right)$ and $0.1 \mathrm{mM}$ potassium dihydrogen phosphate $\left(\mathrm{KH}_{2} \mathrm{PO}_{4}\right)[\mathrm{pH} 7.4$, adjusted with $0.1 \mathrm{M}$ hydrochloric acid $(\mathrm{HCl})$ and 0.1 $\mathrm{M}$ sodium hydroxide $(\mathrm{NaOH})]$. SD WSPFE samples for final concentrations between 0 to $500 \mu \mathrm{g} / \mathrm{mL}$ were prepared. Serial dilutions of phloretin (Cayman Chemical Company, Ann Arbor, Michigan, United States of America) and phloridzin (Cayman Chemical Company, Ann Arbor, Michigan, United States of America) were also prepared as positive controls. Glucose uptake assays were conducted by introducing Ringer's solution into everted mouse intestinal sacs (inner serosal sides) and immersing these sacs into Ringer's solution containing $10 \mathrm{mM}$ of D-glucose as well as each prepared concentration of either one of the positive controls or SD WSPFE (outer mucosal sides) for $30 \mathrm{~min}$. These assays were conducted in a $37^{\circ} \mathrm{C}$ oxygenated $\left[95 \% \mathrm{v} / \mathrm{v}\right.$ oxygen $\left(\mathrm{O}_{2}\right)$ and $5 \% \mathrm{v} / \mathrm{v}$ carbon dioxide $\left.\left(\mathrm{CO}_{2}\right)\right]$ water bath $(\mathrm{Memmert} \mathrm{GmbH}$, Buchenbach, Germany). For the measurement of glucose, samples from the inner serosal sides were collected before and after the glucose uptake assays. Glucose measurement was performed using the Glucose Oxidase Assay Kit (Sigma-Aldrich, Saint Louis, Missouri, United States of America).

\section{Glucose Uptake of Human Colonic Caco-2 Cell Monolayers}

Human colonic Caco-2 cells (ATCC ${ }^{\circledast}$ HTB$37^{\mathrm{TM}}$ ) (passage numbers 20-60) were utilised for 
the in vitro cell culture experiments. Appropriate aseptic mammalian cell culture techniques were applied throughout the cell culture experiments described in this study. The complete medium used for maintenance and subculturing of the cells was Dulbecco's Modified Eagles' Medium (DMEM) containing $10 \% \mathrm{v} / \mathrm{v}$ fetal bovine serum (FBS) and 1\% v/v non-essential amino acids, obtained from Gibco (Thermo Fisher Scientific, Waltham, Massachusetts, United States of America). Dimethyl sulphoxide (DMSO) (Sigma-Aldrich, Saint Louis, Missouri, United States of America) was added at $5 \% \mathrm{v} / \mathrm{v}$ to the complete medium for cell cryopreservation.

For CellTiter-Glo (CTG) luminescent cell viability assays, Caco-2 cells grown to confluence were trypsinised with Gibco trypsin ethylenediaminetetraacetic acid (EDTA) $(0.25 \% \mathrm{w} / \mathrm{v})$ containing phenol red (Thermo Fisher Scientific, Waltham, Massachusetts, United States of America) and centrifuged at $130 \times \mathrm{g}$ for $5 \mathrm{~min}$. Following cell counting, $75 \mu \mathrm{L}$ of complete Gibco DMEM medium containing $2.5 \times 10^{4}$ cells was pipetted into each well of a 96-well white opaque tissue-culture treated microplate (SPL Life Sciences Co. Ltd., Pocheon-si, South Korea). The microplate was then incubated overnight at $37^{\circ} \mathrm{C}$ in a $5 \% \mathrm{v} / \mathrm{v} \quad \mathrm{CO}_{2}$ incubator (NuAire, Inc., Plymouth, Minnesota, United States of America). Appropriate media controls were also prepared in other wells within the same plate. WSPFE samples were prepared the following day using complete Gibco DMEM medium containing $0.4 \% \mathrm{v} / \mathrm{v}$ DMSO as the vehicle. A total of $25 \mu \mathrm{L}$ of each WSPFE sample was added into the wells of the 96-well microplates prepared previously, before being subjected to incubation at $37^{\circ} \mathrm{C}$ in $5 \% \mathrm{v} / \mathrm{v} \mathrm{CO}_{2}$ for $24 \mathrm{hr}$. WSPFE samples were tested at varying final concentrations between 0 to $2000 \mu \mathrm{g} / \mathrm{mL}$ to determine the half maximal inhibitory concentration $\left(\mathrm{IC}_{50}\right)$ values of the samples on Caco-2 cell viability. The CTG Luminescent Cell Viability Assay Kit (Promega Corp., Madison, Wisconsin, United States of America) was used for this purpose.

The protocols used to prepare Caco-2 monolayers were adapted from literature (Hubatsch et al., 2007). Each sterile filter insert in 12-well plates (Corning, New York City, New York, United States of America) was coated with $250 \mu \mathrm{L}$ of type I collagen solution from rat tail (Sigma-Aldrich, Saint Louis, Missouri, United States of America) prepared in $0.02 \mathrm{M}$ acetic acid (Merck KGaA, Darmstadt, Germany) at a coating density of $10 \mu \mathrm{g}$ $\mathrm{cm}^{-2}$. This coating step was carried out at $37^{\circ} \mathrm{C}$ for $1 \mathrm{hr}$. Excess collagen solution was then pipetted out and $400 \mu \mathrm{L}$ of complete Gibco DMEM medium containing $20 \% \mathrm{v} / \mathrm{v}$ FBS, $1 \% \mathrm{v} / \mathrm{v}$ non-essential amino acids and $1 \% \mathrm{v} / \mathrm{v}$ penicillin-streptomycin was then added to each well. The plates were then incubated at $37^{\circ} \mathrm{C}$ for $4 \mathrm{hr}$, after which the medium was removed prior to cell seeding.
Caco-2 cells grown to confluence were then trypsinised with Gibco trypsin-EDTA $(0.25 \% \mathrm{w} / \mathrm{v})$ containing phenol red and centrifuged at $130 x \mathrm{~g}$ for 5 min. Following cell counting, $500 \mu \mathrm{L}$ of complete Gibco DMEM medium containing $3 \times 10^{5}$ cells was pipetted into each collagen-coated filter insert (apical layer). The bottom well (basolateral layer) was filled with $1500 \mu \mathrm{l}$ of complete Gibco DMEM medium. Incubation was then carried out at $37^{\circ} \mathrm{C}$ in $5 \% \mathrm{v} / \mathrm{v} \mathrm{CO}$ overnight before the apical medium was replaced with fresh complete Gibco DMEM medium. Both apical and basolateral media were changed twice a week to allow cell monolayers to form and differentiate for three weeks. The integrity of the cell monolayers was assessed by measuring the transepithelial electrical resistance (TEER) using the Millicell ${ }^{\circledR}$ ERS-2 Voltohmmeter (Merck KGaA, Darmstadt, Germany). Caco-2 monolayers with TEER values $>200 \Omega \mathrm{cm}^{2}$ were used in the glucose uptake experiments.

The chemicals used for glucose uptake experiments were purchased from Sigma-Aldrich (Saint Louis, Missouri, United States of America) unless otherwise stated. One day before the glucose uptake experiments, both apical and basolateral media of the cell monolayers were discarded. The monolayers were then washed with Gibco phosphate buffered saline (Thermo Fisher Scientific, Waltham, Massachusetts, United States of America). Serum-free Gibco DMEM medium containing $1 \% \mathrm{v} / \mathrm{v}$ non-essential amino acids and $1 \% \mathrm{v} / \mathrm{v}$ penicillin-streptomycin was then added to the apical and basolateral sides. The plates were then incubated at $37^{\circ} \mathrm{C}$ in $5 \% \mathrm{v} / \mathrm{v} \mathrm{CO}$ overnight to increase glucose uptake.

The following day, WSPFE samples were dissolved in DMSO and added to serum-free Gibco DMEM medium containing $1 \% \mathrm{v} / \mathrm{v}$ nonessential amino acids and $1 \% \mathrm{v} / \mathrm{v}$ penicillinstreptomycin at a final $0.4 \% \mathrm{v} / \mathrm{v}$ DMSO concentration. The dissolved test compounds were then serially diluted to the concentrations required using serum-free Gibco DMEM medium containing $1 \% \mathrm{v} / \mathrm{v}$ non-essential amino acids, $1 \%$ $\mathrm{v} / \mathrm{v}$ penicillin-streptomycin and $0.4 \% \mathrm{v} / \mathrm{v}$ DMSO. Serial dilutions of phloretin (Cayman Chemical Company, Ann Arbor, Michigan, United States of America) and phloridzin (Cayman Chemical Company, Ann Arbor, Michigan, United States of America) were also prepared as positive controls. Following this, the apical and basolateral media of the cell monolayers were discarded. The prepared test compounds were then added to the apical sides. Serum-free Gibco DMEM medium containing $1 \% \mathrm{v} / \mathrm{v}$ non-essential amino acids, $1 \%$ $\mathrm{v} / \mathrm{v}$ penicillin-streptomycin and $0.4 \% \mathrm{v} / \mathrm{v}$ DMSO was then added to the basolateral sides. The plates were then incubated at $37^{\circ} \mathrm{C}$ in $5 \% \mathrm{v} / \mathrm{v} \mathrm{CO}_{2}$ for $1 \mathrm{hr}$ in acute studies, or $20 \mathrm{hr}$ in chronic studies. 
Following the required incubation time, the test compounds were discarded. The apical and basolateral sides were then washed with glucosefree sodium uptake buffer, which contained $140 \mathrm{mM}$ $\mathrm{NaCl}, 5 \mathrm{mM} \mathrm{KCl}, 2.5 \mathrm{mM} \mathrm{CaCl}, 1 \mathrm{mM}$ magnesium sulphate $\left(\mathrm{MgSO}_{4}\right), 1 \mathrm{mM}$ sodium dihydrogen phosphate $\left(\mathrm{NaH}_{2} \mathrm{PO}_{4}\right), 10 \mathrm{mM}$ 4-(2-hydroxyethyl)1-piperazineethanesulphonic acid (HEPES), 1\% $\mathrm{v} / \mathrm{v}$ L-glutamine, $1 \% \mathrm{v} / \mathrm{v}$ non-essential amino acids and $1 \% \mathrm{v} / \mathrm{v}$ penicillin-streptomycin $(\mathrm{pH}$ 7.4, adjusted with $0.1 \mathrm{M} \mathrm{HCl}$ and $0.1 \mathrm{M} \mathrm{NaOH}$ ). Following the wash step, $250 \mu \mathrm{l}$ of $10 \mathrm{mMD}$-glucose solution prepared in glucose-free sodium uptake buffer was added to the apical sides, while $750 \mu$ l of the glucose-free sodium uptake buffer was added to the basolateral sides. The plates were then incubated at $37^{\circ} \mathrm{C}$ in $5 \% \mathrm{v} / \mathrm{v} \mathrm{CO}_{2}$ for $1 \mathrm{hr}$. Following this, samples from the basolateral sides were collected for glucose measurements. These glucose uptake experiments using human colonic Caco-2 cell monolayers were repeated using sodium-free uptake buffer, whereby $\mathrm{NaCl}$ was replaced with $\mathrm{KCl}$ and $\mathrm{NaH}_{2} \mathrm{PO}_{4}$ was replaced with $\mathrm{KH}_{2} \mathrm{PO}_{4}$. The Glucose Hexokinase Assay Kit (Sigma-Aldrich, Saint Louis, Missouri, United States of America) was used for glucose measurement of samples collected from the basolateral sides of the Caco-2 monolayers.

\section{Assays on Carbohydrate Hydrolysis and Incretin Degradation Enzymes}

The Alpha-Glucosidase Activity Assay Kit (Colorimetric) (ab174093) (Abcam PLC, Cambridge, United Kingdom) was utilised to perform assays on $\alpha$-glucosidase, a carbohydrate-hydrolysing enzyme. Assays on another carbohydrate-hydrolysing enzyme, $\alpha$-amylase, were carried out using the Alpha-Amylase Activity Assay Kit (Colorimetric) (ab102523) (Abcam PLC, Cambridge, United Kingdom). For the incretin degradation enzyme DPPIV, assays were performed using the DPPIVGlo Protease Assay Kit (G8351) (Promega Corp., Madison, Wisconsin, United States of America) and the recombinant human DPPIV high purity dimer enzyme (R\&D Systems, Inc., Minneapolis, Minnesota, United States of America).

WSPFE samples were tested at varying final concentrations between 0 to $500 \mu \mathrm{g} / \mathrm{mL}$ to determine the $\mathrm{IC}_{50}$ values of the samples on $\alpha$-glucosidase, $\alpha$-amylase and DPPIV. Negative control wells containing the substrate and enzyme without inhibitor samples, positive control wells containing the substrate, enzyme and the positive control inhibitor, as well as colour control samples which functioned as blanks for the corresponding samples were also prepared in these experiments. Acarbose (Sigma-Aldrich, Saint Louis, Missouri, United States of America) was used as the positive control inhibitor in the $\alpha$-glucosidase and $\alpha$-amylase assays, while sitagliptin phosphate (Cayman Chemical Company, Ann Arbor, Michigan, United States of America) was used as the positive control inhibitor in the DPPIV assays. Acarbose which is a pseudo-tetrasaccharide obtained from the fermentation processes of the microorganism Actinoplanes utahensis is commonly used as an oral reversible competitive inhibitor of $\alpha$-glucosidase and $\alpha$-amylase enzymes in T2DM patients (Rosak and Mertes, 2012; Yee and Fong, 1996). On the other hand, sitagliptin which is a synthesised beta-amino amide incorporating fused heterocycles called triazolopiperazines is an oral reversible DPPIV inhibitor that is generally well tolerated when administered in T2DM patients (Bergman et al., 2007; Kim et al., 2005).

\section{Statistical Analyses}

Measurements of all enzymatic assays were carried out using the Tecan Infinite M200 microplate reader (Tecan Group Ltd., Zurich, Switzerland). Raw data was exported into the Microsoft Excel software (Microsoft Corp., Redmond, Washington, United States of America) for analysis. Data were expressed as means \pm standard error of the mean (SEM). Statistical analyses on the results obtained were performed using the SPSS Statistics software (IBM Corp., Armonk, New York, United States of America). One-way analysis of variance (ANOVA) with Tukey's honestly significant difference (HSD) post-hoc test or Dunnett's post-hoc test against Negative Control where appropriate was carried out. Differences were considered statistically significant at $p<0.05 . \mathrm{IC}_{50}$ values were calculated using the Quest Graph ${ }^{\mathrm{TM}} \mathrm{IC}_{50}$ Calculator (AAT Bioquest, Inc., Sunnyvale, California, United States of America) (AAT Bioquest, 2019).

\section{RESULTS AND DISCUSSION}

\section{Glucose Uptake of Everted Mouse Intestinal Sacs}

Ex vivo everted mouse intestinal sac preparation protocols from previous studies (Hamilton and Butt, 2013; Mary and Rao, 2002) were adapted to elucidate the possible effects of WSPFE samples on glucose transport, since this model is considered to be one of the efficient tools used for studying intestinal absorption (Alam et al., 2012). However, initial experiments conducted on SD WSPFE samples using ex vivo everted mouse intestinal sacs showed that while positive controls phloretin and phloridzin inhibited glucose transport from the mucosal to the serosal sides of the everted mouse intestinal sacs, SD WSPFE did not have any glucose absorption inhibition effects up to 
(a)

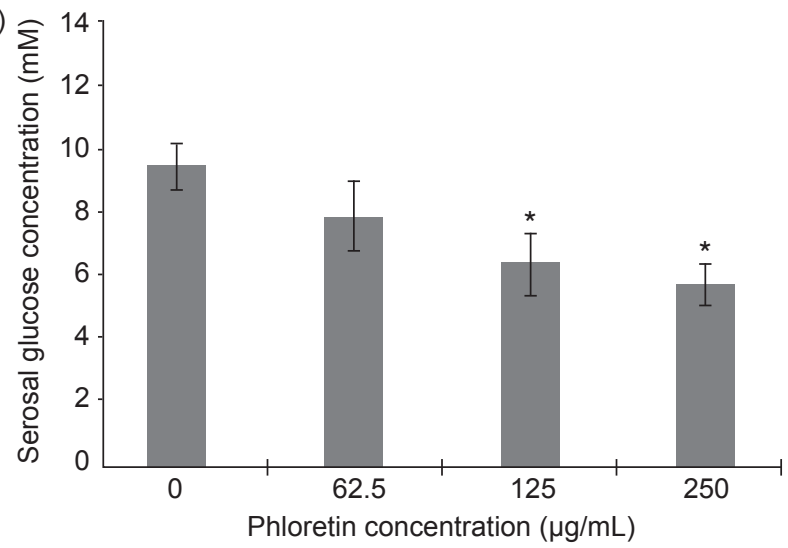

(b)

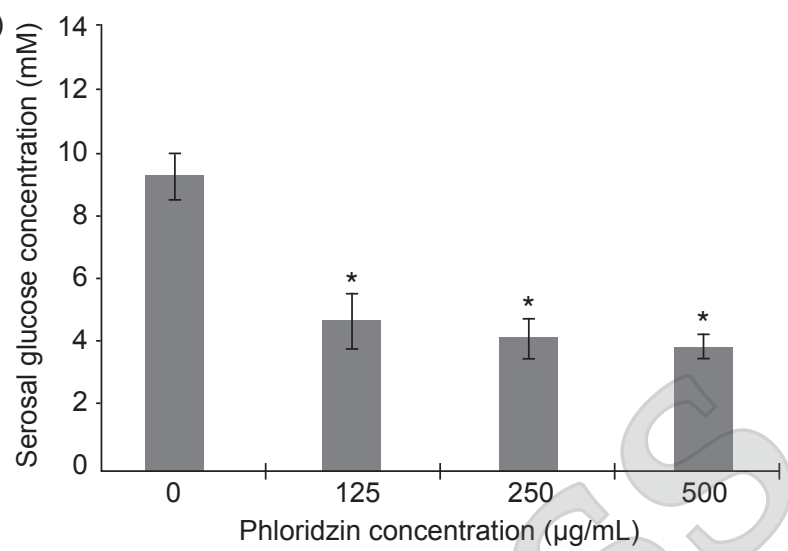

(c)

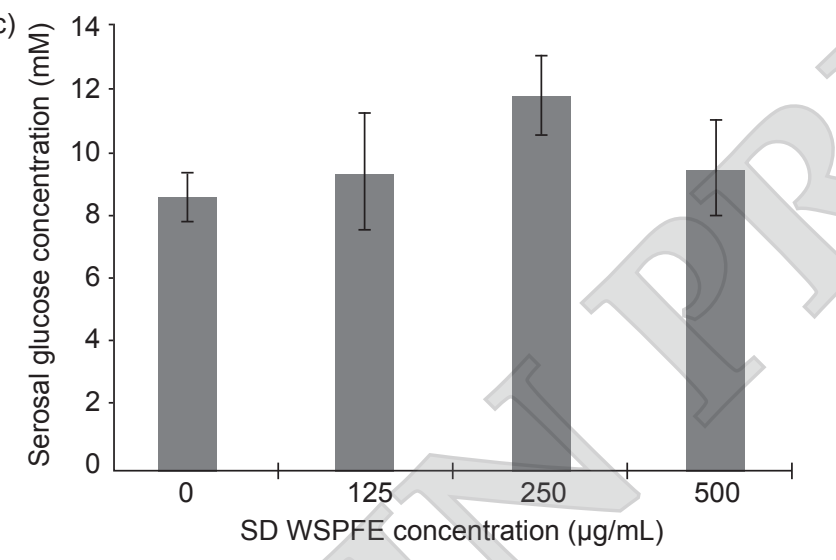

Note: Error bars indicate standard error of the mean (SEM); $n=5$ biological replicates; ${ }^{*} p<0.05$ by one-way analysis of variance (ANOVA) with Dunnett's post-hoc test against Negative Control $(0 \mu \mathrm{g} / \mathrm{mL})$. SD - spray dried; WSPFE - Water-Soluble Palm Fruit Extract.

Figure 1. Glucose uptake assay results on everted mouse intestinal sacs using positive controls and SD WSPFE of different doses as measured using the absorbance-based Glucose Oxidase Assay Kit over the assay time period of 30 min after incubation with the respective test samples for 30 min. (a) Phloretin, (b) phloridzin, and (c) SD WSPFE.

$500 \mu \mathrm{g} / \mathrm{mL}$ (Figure 1). This suggested that the anti-diabetic effects of SD WSPFE were not due to inhibition of glucose absorption in the intestines. To further confirm this and to reduce the use of animals, another model of the intestinal barrier, the in vitro Caco-2 cell monolayer model, was utilised for glucose uptake evaluation. In addition, the glucose hexokinase assay was subsequently used for glucose measurements in the present study, since previous investigations had demonstrated the sensitivity and accuracy of this assay, which results from reduction of colour interference by plant phenolic compounds (Xu et al., 2012).

\section{Preparation of WSPFE Fractions}

Further glucose transport investigations were conducted using in vitro Caco- 2 cell monolayers. In addition to SD WSPFE, additional WSPFE samples were tested in this set of experiments, including FD WSPFE, WSPFE EAF, as well as seven individual WSPFE fractions (F1-F7) isolated using preparative HPLC. These seven individual fractions were prepared as previously described (Leow et al., 2021b) and identification of the major components of the fractions was based on information obtained from our previous published work on WSPFE. F1 contained shikimic acid (Sambandan et al., 2011), F3 contained protocatechuic acid (Sambanthamurthi et al., 2011a), F4 contained $p$-hydroxybenzoic acid (Sambanthamurthi et al., 2011a), F5 contained an indoleacetic acid derivative (Sambanthamurthi et al., 2014), while F6 contained three caffeoylshikimic acid isomers (Sambanthamurthi et al., 2011a). The components of F2 and F7 are presently unknown.

\section{Caco-2 Cell Viability Assays}

In cell viability and cytotoxicity studies, the $\mathrm{IC}_{50}$ of a compound defines its maximum non-toxic dose (Neubig et al., 2003). $\mathrm{IC}_{50}$ thus, acts as a parameter to determine the maximum concentration of a tested compound which could be used to produce desirable effects without exceeding the range of acceptable toxicity. The $\mathrm{IC}_{50}$ value of a tested compound on cell lines is determined by the concentration needed to inhibit half of the maximum viability of the cell lines. 
In the present study, before carrying out glucose uptake assays on Caco-2 cell monolayers, the $\mathrm{IC}_{50}$ values of the WSPFE samples on the viability of the cell line were determined using the CTG Luminescent Cell Viability Assay Kit. The positive control phloridzin, SD WSPFE, FD WSPFE, WSPFE EAF and F1 were not cytotoxic to Caco-2 cells after incubation up to $2000 \mu \mathrm{g} / \mathrm{mL}$ for $24 \mathrm{hr}$ (Table 1). On the other hand, the positive control phloretin and F2 to F7 showed cytotoxicity on the Caco-2 cells after incubation for $24 \mathrm{hr}$. F2 had an $\mathrm{IC}_{50}$ value of $1265 \pm$ $107 \mu \mathrm{g} / \mathrm{mL}$, while F3 had an $\mathrm{IC}_{50}$ value of $544 \pm 48$ $\mu \mathrm{g} / \mathrm{mL}$. The $\mathrm{IC}_{50}$ value of $\mathrm{F} 4$ was $1007 \pm 99 \mu \mathrm{g} / \mathrm{mL}$, while F5 had an $\mathrm{IC}_{50}$ value of $666 \pm 107 \mu \mathrm{g} / \mathrm{mL}$. F6 had an $\mathrm{IC}_{50}$ value of $571 \pm 178 \mu \mathrm{g} / \mathrm{mL}$, while the last fraction, $\mathrm{F} 7$, had an $\mathrm{IC}_{50}$ value of $737 \pm 78 \mu \mathrm{g} / \mathrm{mL}$. The positive control phloretin was most toxic to the Caco-2 cells, with an $\mathrm{IC}_{50}$ value of $131 \pm 31 \mu \mathrm{g} / \mathrm{mL}$.

As such, the levels of cytotoxicity of WSPFE samples on Caco-2 cells followed the order of SD $\mathrm{WSPFE}=\mathrm{FD}$ WSPFE $=$ WSPFE EAF $=\mathrm{F} 1<\mathrm{F} 2<\mathrm{F} 4$ $<\mathrm{F} 7<\mathrm{F} 5<\mathrm{F} 6<\mathrm{F} 3$. The results obtained suggested that the concentrations of WSPFE samples to be used in the glucose uptake experiments should

\begin{tabular}{lc}
\multicolumn{2}{c}{$\begin{array}{c}\text { TABLE 1. IC } \\
\text { CA VALUES OF WSPFE SAMPLES AGAINST } \\
\text { CACO-2 CELL VIABILITY }\end{array}$} \\
\hline Sample & IC $_{50}(\mu \mathrm{g} / \mathrm{mL})$ \\
\hline SD WSPFE & $*$ \\
FD WSPFE & $*$ \\
WSPFE EAF & $*$ \\
F1 & $*$ \\
F2 & $1265 \pm 107^{\mathrm{a}}$ \\
F3 & $544 \pm 48^{\mathrm{bc}}$ \\
F4 & $1007 \pm 99^{\mathrm{ab}}$ \\
F5 & $666 \pm 107^{\mathrm{b}}$ \\
F6 & $571 \pm 178^{\mathrm{bc}}$ \\
F7 & $737 \pm 78^{\mathrm{b}}$ \\
Phloretin & $131 \pm 31^{\mathrm{c}}$ \\
Phloridzin & $*$ \\
\hline
\end{tabular}

Note: $\mathrm{IC}_{50}$ indicates the dose that induced a $50 \%$ cell viability inhibition compared to Negative Control as measured using the luminescence-based CTG Luminescent Cell Viability Assay Kit over $10 \mathrm{~min}$ after incubation with the respective test samples up to $2000 \mu \mathrm{g} / \mathrm{mL}$ for $24 \mathrm{hr}$. These $\mathrm{IC}_{50}$ values were expressed as means \pm standard error of the mean (SEM) from three biological replicates. Means in a column with different letters are significantly different $(p<0.05)$ by one-way analysis of variance (ANOVA) with Tukey's honestly significant difference (HSD) posthoc test. *indicates $\mathrm{IC}_{50}$ was not achieved at the highest concentration tested $(2000 \mu \mathrm{g} / \mathrm{mL})$. EAF - ethyl acetate fraction; F - fraction; FD - freeze dried; SD - spray dried; WSPFE - Water-Soluble Palm Fruit Extract. be up to $500 \mu \mathrm{g} / \mathrm{mL}$, as the $\mathrm{IC}_{50}$ value of the most cytotoxic WSPFE sample, F3, was $544 \pm 48 \mu \mathrm{g} / \mathrm{mL}$. This would help to determine the effects of these samples in influencing glucose absorption, by discounting their effects on cell viability. Caco-2 cell monolayers have been widely used to determine the effects of dietary phenolic compounds on glucose transport (Alzaid et al., 2013; Farrell et al., 2013; Johnston et al., 2005; Manzano and Williamson, 2010), as these cells abundantly express the active sodium-dependent glucose transporter 1 (SGLT1) and facilitated glucose transporter 2 (GLUT2) proteins (Sambuy et al., 2005). Nevertheless, it should be noted that Caco-2 is a human cell line derived from human colon adenocarcinoma cancer tissues, and thus, these immortalised cell lines may have their own characteristics which may not be typical of primary cultures.

It is also interesting to note that the toxicity effects of F2 to F7 at various concentrations suggest the potential use of these fractions against colon cancer. Many studies have shown that phenolic acids were able to inhibit cancer (Abotaleb et al., 2020), including colon cancer (Rosa et al., 2016). The cell viability results obtained in the present study showed that F3 containing protocatechuic acid was more cytotoxic to the Caco-2 cells as compared to fractions containing the caffeoylshikimic acid isomers, the indoleacetic acid derivative and $p$-hydroxybenzoic acid. Protocatechuic acid was shown to be a potential cancer chemopreventive agent (Tanaka et al., 2011), as it exerted pro-apoptotic and anti-proliferative effects (Kakkar and Bais, 2014). 3-O-caffeoylshikimic acid and 5-O-caffeoylshikimic acid from the fruits of the Chinese fan or fountain palm (Livistona chinensis) were shown to have potent anti-proliferative activities against several cancer cell lines (Zeng et al., 2012). Indoleacetic acid was also found to induce cancer cell death in combination with horseradish peroxidase (Wardman, 2002) or ultraviolet B irradiation (Kim et al., 2010). Derivatives of $p$-hydroxybenzoic acid also exhibited anti-cancer activities (Seidel et al., 2014).

Key structural motifs in phenolic acids responsible for anti-cancer activities include the aromatic ring, number and position of free hydroxyl groups and unsaturated fatty acid chains (Anantharaju et al., 2016). The simpler structure of protocatechuic acid containing an aromatic ring attached with one free hydroxyl group might have contributed to the cytotoxicity effects of F3, but future in silico molecular docking experiments would be helpful to better explain the structure-activity relationships between the individual compounds present in WSPFE and potential anti-cancer molecular targets (Chen et al., 2012). However, it would be important to note that F1-F7 used in the present study were not 
pure compounds, but only fractions enriched in the compounds mentioned. Therefore, their effects might not only be attributable to the compounds, but also to unidentified non-phenolic compounds and/or the complex nature of these fractions and interactions between phytochemicals present in them.

The cytotoxic properties of the WSPFE samples demonstrated in the present study are also consistent with the anti-cancer effects of WSPFE previously identified, in which FD WSPFE exhibited inhibitory effects on human A549 lung carcinoma, human MCF7 breast adenocarcinoma and mouse J558 immunoglobulin A-secreting myeloma cell lines (Sekaran et al., 2010) when tested up to 2000 $\mu \mathrm{g} / \mathrm{mL}$. Nevertheless, FD WSPFE did not have an effect on the cell viability of the Caco- 2 cells used in the present study when tested up to 2000 $\mu \mathrm{g} / \mathrm{mL}$. This suggests that FD WSPFE may not be as effective against human colon adenocarcinoma cancer as compared to other types of cancer. As such, additional experiments in the future on other types of colon cancer cell lines and on normal colon cell lines would be required to further supplement the present findings.

\section{Glucose Uptake of Human Colonic Caco-2 Cell Monolayers}

The uptake of glucose in the gastrointestinal tract occurs via the enterocyte membrane transporters SGLT1 and GLUT2. SGLT1 is involved in active glucose transport from the apical side of the intestinal lumen into enterocytes, while GLUT2 is involved in facilitated glucose diffusion from the basolateral side of the intestinal lumen into the hepatic portal vein (Scheepers et al., 2004).

In the present study, positive controls phloretin and phloridzin dose-dependently inhibited glucose transport from the apical sides to the basolateral sides of the Caco-2 monolayers when tested in both sodium uptake buffer (Figure 2) and sodium-free uptake buffer (Figure 3). When tested using sodium uptake buffer, the inhibitory effects of phloretin on glucose up take were more pronounced during acute treatment (Figure 2a), while those of phloridzin were more pronounced during chronic treatment (Figure 2b). On the other hand, SD WSPFE and FD WSPFE did not show any glucose absorption inhibition effects up to $500 \mu \mathrm{g} / \mathrm{mL}$ during acute treatment (Figure 2c) or chronic treatment (Figure $2 d$ ). In addition, glucose uptake assays carried out using WSPFE EAF and F1-F7 up to $500 \mu \mathrm{g} / \mathrm{mL}$ also did not show any effects of the WSPFE fractions on glucose uptake during acute treatment (Figure $2 e$ ) or chronic treatment (Figure 2f). Similar results were obtained when glucose uptake assays were performed on the Caco- 2 cell monolayers using sodium-free uptake buffer (Figures 3a-f). These results implied that the anti-diabetic effects of WSPFE were not due to glucose uptake inhibition, and hence other mechanisms might be involved instead.

Although phloretin is known to inhibit GLUT2 and phloridzin is known to inhibit SGLT1 (and also renal SGLT2) (Ehrenkranz et al., 2005), we did not find any differences in terms of the inhibitory patterns of these positive controls when using sodium uptake buffer or sodium-free uptake buffer in the present study (Figures $2 a-b$ and $3 a-b)$. The strong acute inhibitory effects of phloretin on glucose uptake compared to the strong chronic inhibitory effects of phloridzin observed in the present study would most likely be due to the degradation of phloridzin to its phloretin and glucose moieties (Ehrenkranz et al., 2005), which increased the availability of phloretin in inhibiting glucose uptake of the Caco- 2 cell monolayers.

\section{Assays on Carbohydrate Hydrolysis and Incretin Degradation Enzymes}

The $\mathrm{IC}_{50}$ results obtained from the $\alpha$-glucosidase assays showed that F2, WSPFE EAF, F1, F5, F3 and F4 inhibited this enzyme more significantly than the positive control acarbose, while SD WSPFE, FD WSPFE, F6 and F7 did not (Table 2). F2 and WSPFE EAF inhibited $\alpha$-glucosidase the most, with F2 having stronger inhibitory effects compared to WSPFE EAF, as indicated by their $\mathrm{IC}_{50}$ values of $162 \pm 23 \mu \mathrm{g} / \mathrm{mL}$ and $179 \pm 11 \mu \mathrm{g} / \mathrm{mL}$, respectively.

The $\mathrm{IC}_{50}$ results obtained from the $\alpha$-amylase assays showed that WSPFE EAF, SD WSPFE, F7, FD WSPFE and F5 inhibited this enzyme, but their inhibitory activities were significantly weaker than that of the positive control acarbose by several orders of magnitude. On the other hand, F1, F2, F3, F4 and F6 did not inhibit $\alpha$-amylase (Table 2). Among the WSPFE samples which inhibited $\alpha$-amylase, WSPFE EAF inhibited the enzyme the most, as indicated by its lowest $\mathrm{IC}_{50}$ value of $108 \pm 13 \mu \mathrm{g} /$ $\mathrm{mL}$. This was followed by SD WSPFE and F7, as indicated by their $\mathrm{IC}_{50}$ values of $158 \pm 1 \mu \mathrm{g} / \mathrm{mL}$ and $160 \pm 2 \mu \mathrm{g} / \mathrm{mL}$, respectively. As such, WSPFE EAF which contained all the seven individual WSPFE fractions had the strongest inhibitory effects on this enzyme, as compared to whole SD WSPFE and FD WSPFE samples. Nevertheless, SD WSPFE had stronger inhibitory effects on $\alpha$-amylase as compared to FD WSPFE. In terms of individual fractions, F7 followed by F5 inhibited $\alpha$-amylase the most, but their inhibitory effects were generally weaker than that of WSPFE EAF.

Acarbose is a known anti-hyperglycaemic agent which acts by inhibiting starch digestion enzymes and is widely used in combination with other anti-diabetic drugs (Derosa and Maffioli, 2012). Acarbose is known to inhibit $\alpha$-amylase 
(a)

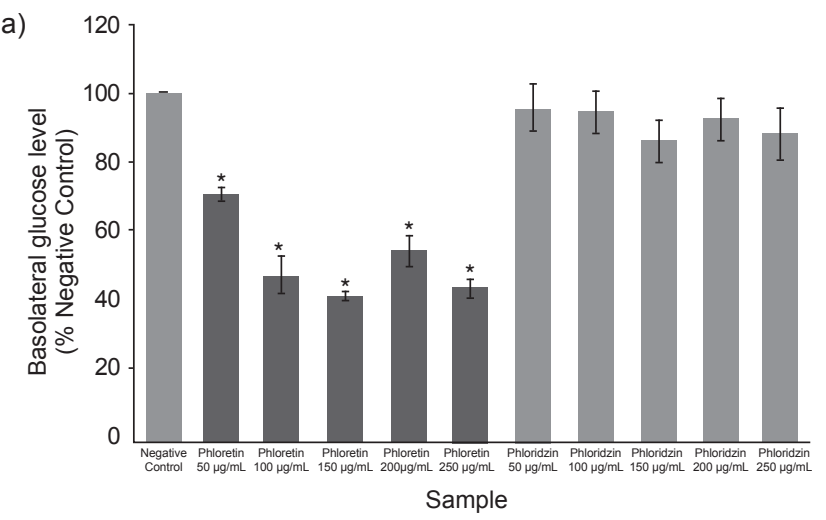

(c)

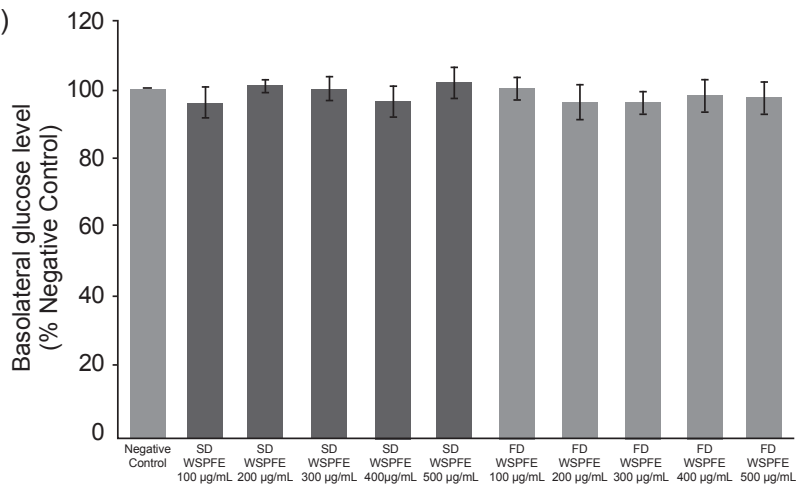

Sample

(e)

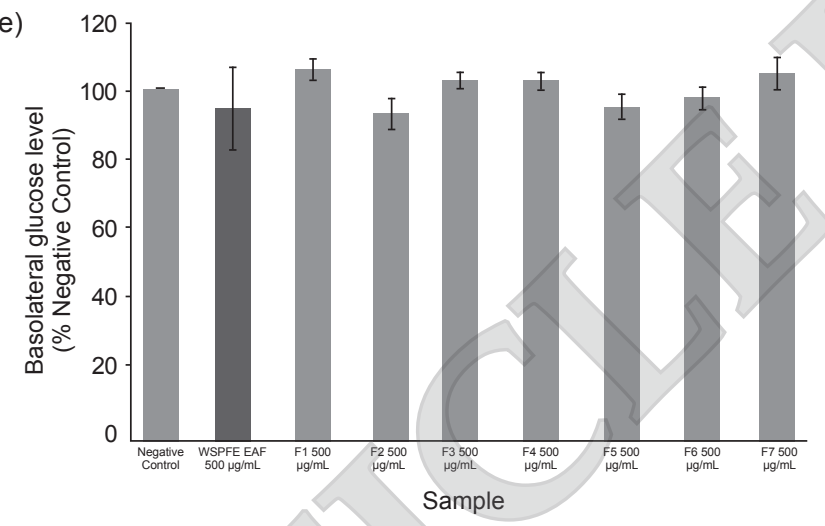

(b)

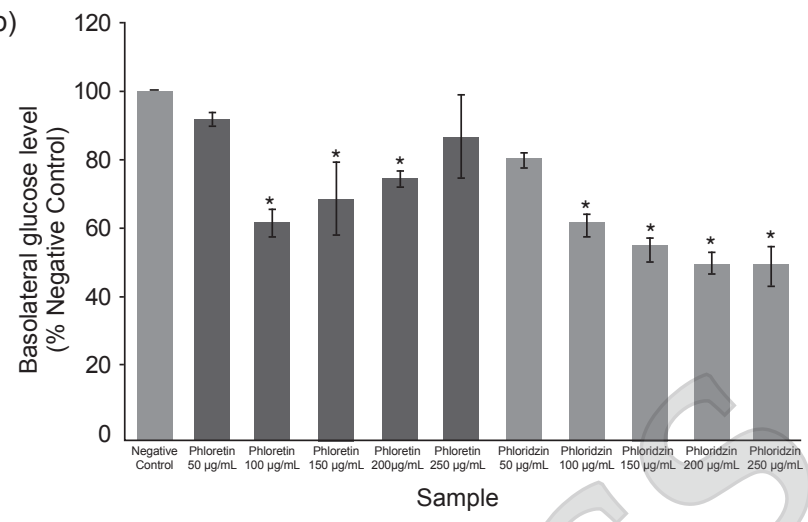

(d)

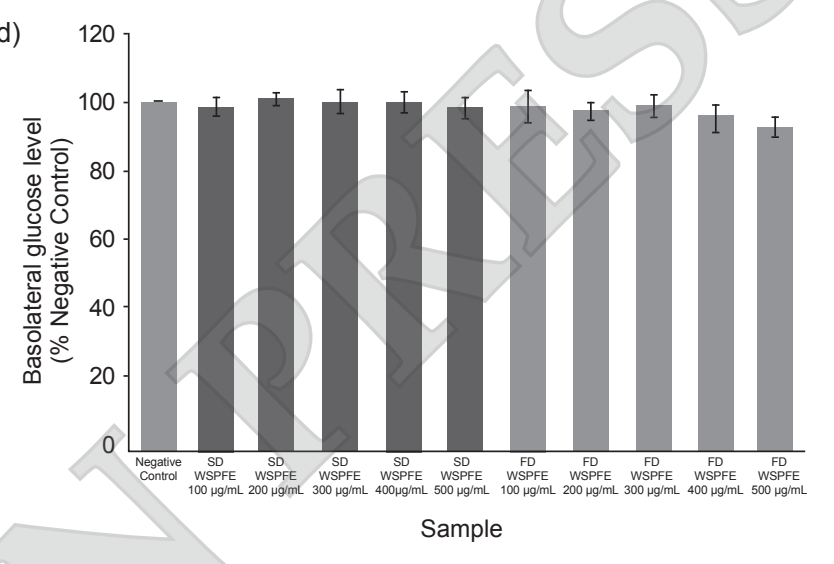

(f)

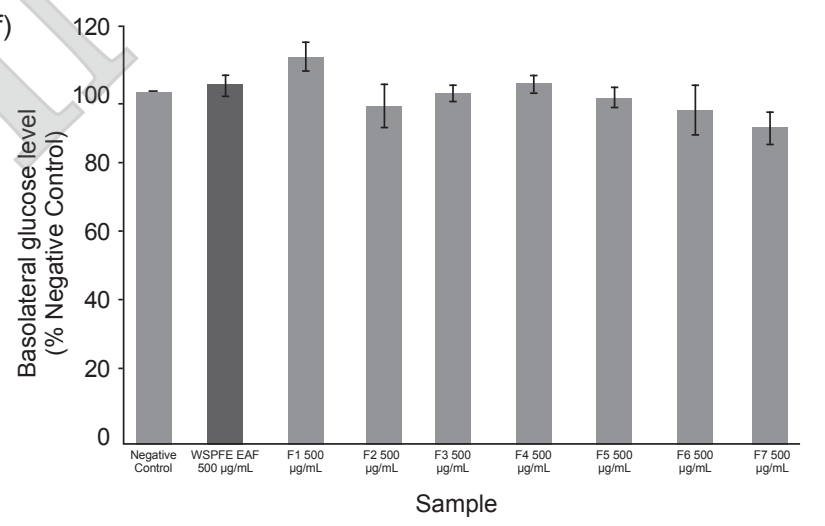

Note: Error bars indicate standard error of the mean (SEM); $n=3$ biological replicates; * $p<0.05$ by one-way analysis of variance (ANOVA) with Dunnett's post-hoc test against Negative Control. EAF - ethyl acetate fraction; F - fraction; FD - freeze dried; SD - spray dried; WSPFE - Water-Soluble Palm Fruit Extract.

Figure 2. Glucose uptake assay results on human colonic Caco-2 cell monolayers in sodium uptake buffer as measured using the absorbance-based Glucose Hexokinase Assay Kit over the assay time period of $30 \mathrm{~min}$ after incubation with the respective test samples. (a) Different doses of positive controls phloretin and phloridzin in 1-hr acute treatment, (b) different doses of positive controls phloretin and phloridzin in 20-hr chronic treatment, (c) different doses of SD WSPFE and FD WSPFE in 1-hr acute treatment, (d) different doses of SD WSPFE and FD WSPFE in 20-hr chronic treatment, (e) WSPFE EAF and F1-F7 (500 $\mathrm{\mu g} / \mathrm{mL})$ in 1-hr acute treatment, and (f) WSPFE EAF and F1-F7 (500 $\mu \mathrm{g} / \mathrm{mL})$ in 20-hr chronic treatment.

significantly more than it inhibits $\alpha$-glucosidase (Oboh et al., 2016). However, strong $\alpha$-amylase inhibitors such as acarbose cause unpleasant side effects including flatulence, bloating and abdominal distention, due to suppression of starch digestion and bacterial fermentation in the gut (Yee and Fong, 1996). As such, anti-hyperglycaemic agents, drugs or phytochemicals should ideally have mild $\alpha$-amylase inhibition but moderate $\alpha$-glucosidase inhibition, in order to minimise their side effects. In line with this, bound polyphenol fractions from date (Phoenix dactylifera L.) seeds for example, were found to have strong $\alpha$-glucosidase inhibition but weak $\alpha$-amylase inhibition (Sirisena et al., 2016). Similar results were found for ethyl acetate extract from the roots of Smilax glabra Roxb, an Asian medicinal plant used for the treatment of various chronic diseases (Nguyen et al., 2020b). 
(a)

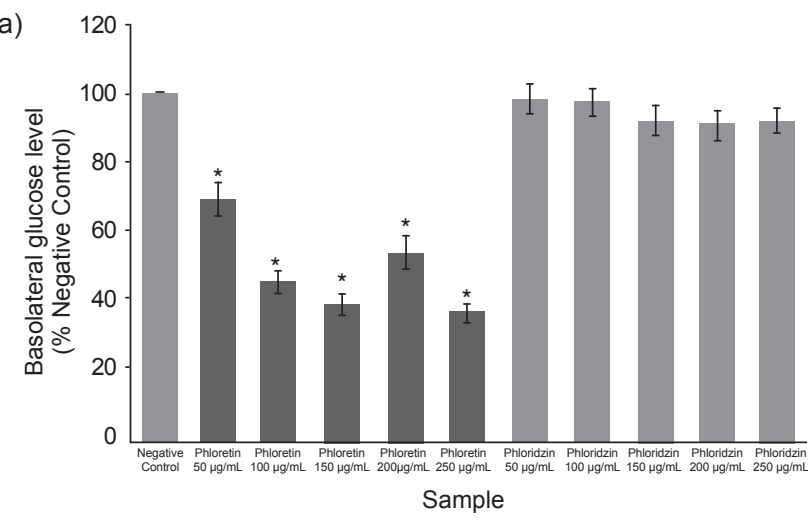

(c)

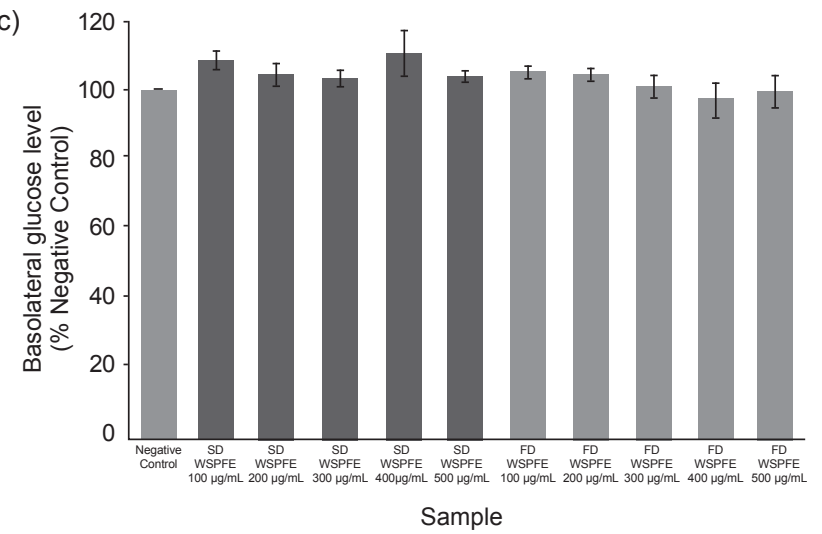

(e)

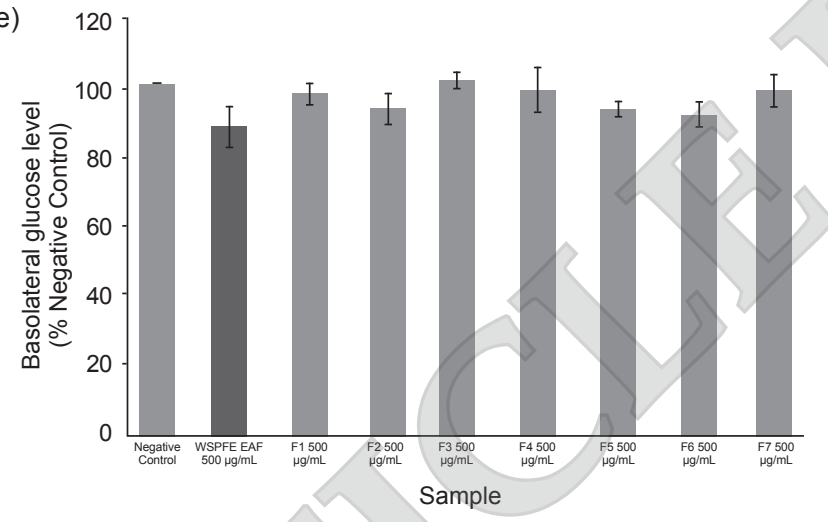

(b)

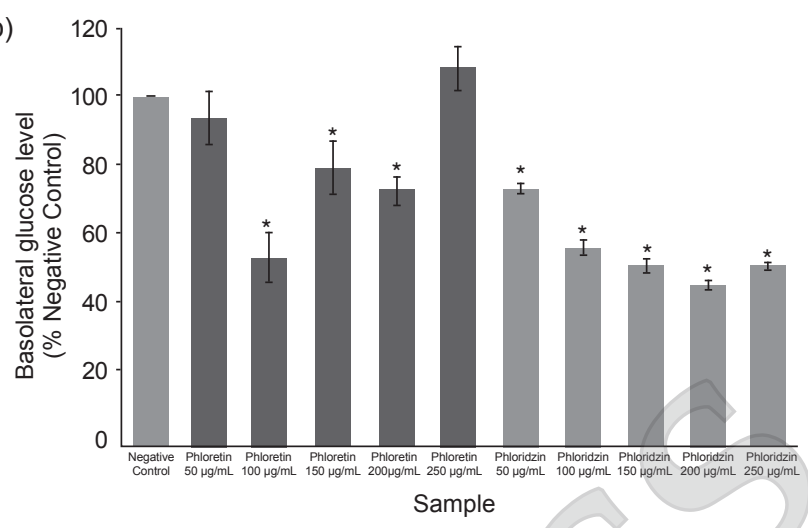

(d)

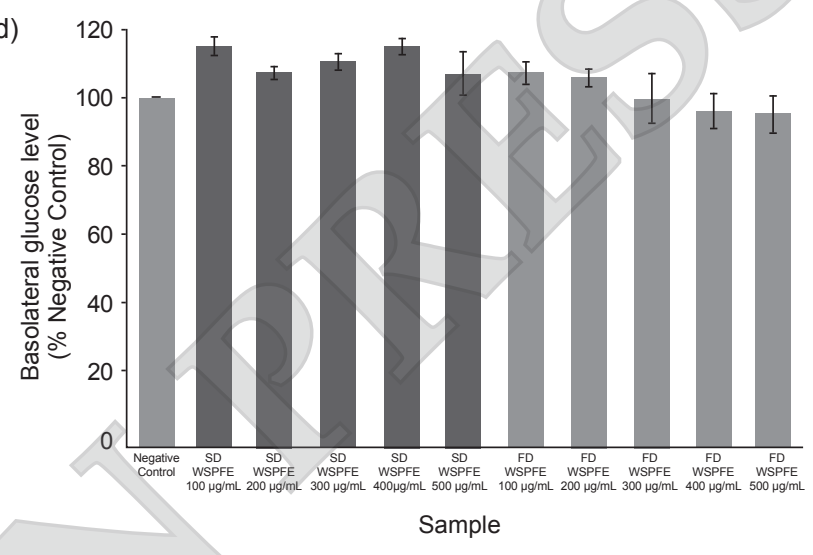

(f)

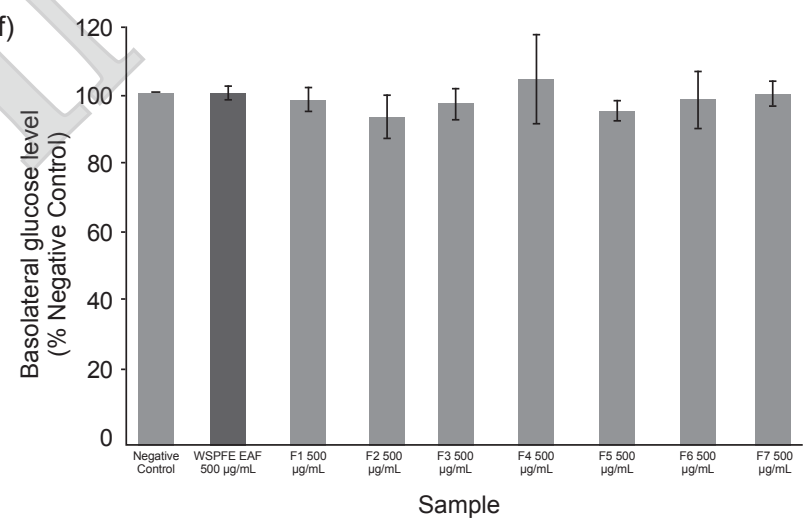

Note: Error bars indicate standard error of the mean (SEM); $n=3$ biological replicates; * $p<0.05$ by one-way analysis of variance (ANOVA) with Dunnett's post-hoc test against Negative Control. EAF - ethyl acetate fraction; F - fraction; FD - freeze dried; SD - spray dried; WSPFE - Water-Soluble Palm Fruit Extract.

Figure 3. Glucose uptake assay results on human colonic Caco-2 cell monolayers in sodium-free uptake buffer as measured using the absorbance-based Glucose Hexokinase Assay Kit over the assay time period of 30 min after incubation with the respective test samples. (a) Different doses of positive controls phloretin and phloridzin in 1-hr acute treatment, (b) different doses of positive controls phloretin and phloridzin in 20-hr chronic treatment, (c) different doses of SD WSPFE and FD WSPFE in 1-hr acute treatment, (d) different doses of SD WSPFE and FD WSPFE in 20-hr chronic treatment, (e) WSPFE EAF and F1-F7 $(500 \mu \mathrm{g} / \mathrm{mL})$ in 1-hr acute treatment, and (f) WSPFE EAF and F1-F7 (500 $\mu \mathrm{g} / \mathrm{mL})$ in 20-hr chronic treatment.

In the present study, SD WSPFE and FD WSPFE inhibited $\alpha$-amylase but not $\alpha$-glucosidase. These results indicate that the anti-diabetic effects of WSPFE may be due to $\alpha$-amylase inhibition and not $\alpha$-glucosidase inhibition, especially more so when SD WSPFE is supplemented. WSPFE EAF and most of the individual WSPFE fractions, as compared to the positive control acarbose, had stronger inhibitory effects on $\alpha$-glucosidase but weaker inhibitory effects on $\alpha$-amylase. Several of the individual WSPFE fractions, i.e. F1-F5, also preferably inhibited $\alpha$-glucosidase than $\alpha$-amylase, hence these fractions might be better anti-diabetic oral supplement candidates worthy of further investigations.

The $\mathrm{IC}_{50}$ results obtained from the DPPIV assays showed that F2, F5, F4, WSPFE EAF and F3 inhibited this enzyme, while SD WSPFE, FD WSPFE, F1, F6 and F7 did not (Table 2). F2 inhibited DPPIV the most, as indicated by its lowest $\mathrm{IC}_{50}$ value of $162 \pm 7$ 
TABLE 2. IC S0 $_{50}$ VALUES OF WSPFE SAMPLES AGAINST $\alpha$-GLUCOSIDASE, $\alpha$-AMYLASE AND DPPIV

\begin{tabular}{|c|c|c|c|}
\hline \multirow{2}{*}{ Sample } & \multicolumn{3}{|c|}{$\mathrm{IC}_{50}(\mu \mathrm{g} / \mathrm{mL})$} \\
\hline & $\alpha$-glucosidase & $\alpha$-amylase & DPPIV \\
\hline SD WSPFE & * & $158 \pm 1^{b}$ & * \\
\hline FD WSPFE & * & $232 \pm 13^{a}$ & * \\
\hline WSPFE EAF & $179 \pm 11^{b}$ & $108 \pm 13^{b}$ & $224 \pm 6^{\mathrm{b}}$ \\
\hline $\mathrm{F} 1$ & $210 \pm 10^{\mathrm{b}}$ & * & * \\
\hline $\mathrm{F} 2$ & $162 \pm 23^{b}$ & * & \\
\hline F3 & $213 \pm 18^{b}$ & * & \\
\hline $\mathrm{F} 4$ & $214 \pm 18^{\mathrm{b}}$ & * & \\
\hline F5 & $210 \pm 13^{b}$ & $239 \pm 29^{a}$ & \\
\hline F6 & * & * & \\
\hline F7 & * & $160 \pm 2^{b}$ & \\
\hline Positive Control & $440 \pm 64^{a}$ & $0.324 \pm 0.016^{c}$ & $33 \pm 0.00$ \\
\hline
\end{tabular}

Note: $\mathrm{IC}_{50}$ indicates the dose that induced a 50\% enzymatic inhibition compared to Negative Control as measured using the respective enzymatic assays kits over $60 \mathrm{~min}$. These $\mathrm{IC}_{50}$ values were expressed as means \pm standard error of the mean (SEM) from three technical replicates. Means in a column with different letters are significantly different $(p<0.05)$ by one-way analysis of variance (ANOVA) with Tukey's honestly significant difference (HSD) post-hoc test. * indicates $\mathrm{IC}_{50}$ was not achieved at the highest concentration tested $(500 \mu \mathrm{g} / \mathrm{mL})$. Acarbose was used as the positive control for $\alpha$-glucosidase and $\alpha$-amylase assays, while sitagliptin was used as the positive control for DPPIV assays. DPPIV - dipeptidyl peptidase-4; EAF - ethyl acetate fraction; F - fraction; FD - freeze dried; SD spray dried; WSPFE - Water-Soluble Palm Fruit Extract.

$\mu \mathrm{g} / \mathrm{mL}$. This was followed by F5 and F4, as indicated by their $\mathrm{IC}_{50}$ values of $185 \pm 4 \mu \mathrm{g} / \mathrm{mL}$ and $196 \pm 2 \mu \mathrm{g} / \mathrm{mL}$, respectively. WSPFE EAF which contained all the seven individual WSPFE fractions was also found to have better inhibitory effects on DPPIV, as compared to SD WSPFE and FD WSPFE. In terms of individual fractions, F2 followed by F5, F4 and F3 inhibited DPPIV the most with their inhibitory effects being generally stronger than those of WSPFE EAF, except for F3. However, the inhibitory effects of all the WSPFE samples towards DPPIV were several orders of magnitude less effective than that of the positive control sitagliptin, which had an $\mathrm{IC}_{50}$ value of $0.006333 \pm 0.000384 \mu \mathrm{g} / \mathrm{mL}$.

The incretin effect, which refers to the amplification of insulin secretion after oral vs. intravenous glucose, is responsible for the disposal of most ingested glucose and is hence, essential for glucose tolerance. It is mainly due to the actions of the gut hormones GIP and GLP-1. GIP is essential for insulin secretion, while GLP-1 is important for inhibition of glucagon secretion (Holst, 2019). DPPIV inhibitors help to protect both GIP and GLP-1 from degradation, hence suppress postprandial glucagon release, delay gastric emptying and regulate satiety (Singh et al., 2017). Natural phenolic compounds such as curcumin have been shown to reduce blood glucose via DPPIV inhibition as one of their mechanisms (Huang et al., 2019).
In the present study, WSPFE EAF and most of the individual WSPFE fractions inhibited DPPIV, although their inhibitory effects were several orders of magnitude less effective than that of the positive control sitagliptin. Clinical studies to date indicate that DPPIV inhibitors increase native GLP-1 to effectively improve glucose control. These agents have low adverse effects and are well tolerated (Ling et al., 2019), hence they could be better than $\alpha$-glucosidase inhibitors for improved glycaemic control and lower gastrointestinal side effects in T2DM patients (Li et al., 2019).

Among the individual WSPFE fractions, F2 demonstrated the strongest inhibitory effects against both DPPIV and $\alpha$-glucosidase, but not $\alpha$-amylase. However, the components in F2 are presently unknown. On the other hand, F7 only inhibited $\alpha$-amylase, similar to SD WSPFE and FD WSPFE, but the components of F7 are also unknown. Further studies on the components in these two fractions are warranted.

F1 which contained shikimic acid was found to only inhibit $\alpha$-glucosidase in the present study, although shikimic acid itself was found inactive as an $\alpha$-glucosidase inhibitor in a previous study (Pham et al., 2014). However, this discrepancy might be because a fraction, and not pure shikimic acid was used in the present study. In line with this, Juniperus oxycedrus subsp. oxycedrus berry extracts containing shikimic acid were previously shown to be hypoglycaemic (Orhan et al., 2012). 
F5 which contained an indoleacetic acid derivative was shown to inhibit all three $\alpha$-glucosidase, $\alpha$-amylase and DPPIV enzymes, in the present study. However, its quantity in WSPFE is the most limited. Indole compounds, which are aromatic nitrogen-containing heterocyclic organic compounds each consisting of a six-membered benzene ring fused to a five-membered pyrrole ring, have been found to a have potential anti-diabetic activities (Zhu et al., 2021), including $\alpha$-glucosidase and $\alpha$-amylase inhibitory properties (Sravanthi et al., 2017).

F4 containing $p$-hydroxybenzoic acid and F3 containing protocatechuic acid had lower $\alpha$-glucosidase and DPPIV inhibitory activities compared to F5. These phenolic acids have two and one hydroxyl groups attached to benzoic acid, respectively. $p$-hydroxybenzoic acid was shown to possess $\alpha$-glucosidase inhibitory activities in a previous study (Ablat et al., 2017). On the other hand, protocatechuic acid was previously shown to inhibit $\alpha$-amylase more than $\alpha$-glucosidase (Adefegha et al., 2015). But this might be because a fraction, and not pure protocatechuic acid was used in the present study.

For $\alpha$-glucosidase inhibition, hydroxyl groups in phenolic compounds such as flavonoids play an important role in binding with $\alpha$-glucosidase (Sun and Miao, 2020). On the other hand, methyl and acetate groups decrease this binding (Sarian et al., 2017). For DPPIV inhibition, hydrogen bonding was found to be the main binding mode of all berry and citrus phenolic compounds tested in a previous study (Fan et al., 2013). It would again be helpful to perform in silico molecular docking experiments in the future to identify the molecular mechanistics of enzymatic inhibition by the major compounds in WSPFE, as well as the structure-activity relationships of individual compounds with these enzymes (Kim et al., 2018; Rasouli et al., 2017).

The $\alpha$-amylase inhibitory activities of WSPFE samples found in the present study might be caused by non-phenolic rather than the phenolic compounds present in WSPFE samples, in line with a previous study on extracts obtained from bioprocessed pineapple and guava wastes, whereby $\alpha$-amylase inhibition was caused by the presence of specific compounds, phenolic or not, rather than by the actual concentration of overall fruit phenolics (Sousa and Correia, 2012). Nevertheless, there might still be direct interactions between dietary plant phenolic compounds on starch properties and starch digestion (Sun and Miao, 2020). These might alter starch physical properties and micromolecular arrangements, such as its morphology, hydrogen bond intensity, crystalline structure, thermal stability and spatial configuration (Chen et al., 2020).
F6 which contained three caffeoylshikimic acid isomers did not show inhibitory activities against $\alpha$-glucosidase, $\alpha$-amylase or DPPIV. This was in contrast with a previous study which showed that kitul palm (Caryota urens L.) inflorescence extract containing caffeoylshikimic acid isomers had significant $\alpha$-glucosidase and $\alpha$-amylase inhibitory properties (Ferreres et al., 2021). However, these kitul extracts not only contained caffeoylshikimic acid isomers, but caffeoylquinic acid isomers as well, the latter of which have been shown to have inhibitory effects towards carbohydratehydrolysing enzymes (Nyambe-Silavwe and Williamson, 2018).

\section{Bioactivity Comparison Summary of Various WSPFE Samples}

Different forms of plant phenolic compounds may confer different anti-diabetic effects. These mechanisms may also vary from one extract or component to another and they may thus, be harnessed to maximise the anti-diabetic effects of these compounds. In the present study, all of the WSPFE samples tested did not inhibit glucose transport, but several had inhibitory effects on $\alpha$-glucosidase, $\alpha$-amylase and DPPIV. It is interesting to note that SD WSPFE had stronger inhibitory effects on $\alpha$-amylase as compared to FD WSPFE. Drying is a major food processing operation to increase shelf life. The choice of drying method however influences product quality, as it is related to the retention of bioactive compounds and biological activities (Abascal et al., 2005). In spray drying, moisture is removed by rapid evaporation on spray droplet under high temperature exposure using hot gas. It is the preferred drying method for thermally sensitive materials such as foods and pharmaceuticals (Verma and Singh, 2015). Conversely, freeze drying involves water removal by sublimation under low pressure (Santo et al., 2013), where much water is removed. This makes a product lightweight, prevents the survival of yeast and bacteria in it, as well as retains its taste, shape and appearance when water is reintroduced. However, freeze drying equipment is expensive, while the process is very time-consuming and labour-intensive. The results obtained in the present study suggest that the spray drying technique is preferable compared to the freeze drying technique in order to retain the potential anti-diabetic bioactivities of WSPFE.

On the other hand, WSPFE EAF had stronger inhibitory effects in all three enzymatic assays carried out, as compared to both SD WSPFE and FD WSPFE. WSPFE contains various components including phenolic acids, indoleacetic acid derivative, shikimic acid, fibre, etc., while its EAF had a higher phenolic content (Leow et al., 2021b). 
When compared to most individual WSPFE fractions, WSPFE EAF also consistently inhibited all the three enzymes tested, the other being F5. This suggests that the seven individual WSPFE fractions when given together as WSPFE EAF had additive or synergistic inhibitory effects against these enzymes and may work better in attenuating diabetes as compared to giving individual WSPFE fractions, or even whole WSPFE samples. It was also interesting to note that while WSPFE EAF consistently inhibited all three enzymes tested in the present study, it was not cytotoxic to the Caco-2 colon cancer cells, although additional experiments on normal colon cell lines would be useful to indicate the implied safety of WSPFE EAF.

In terms of individual WSPFE fractions, F2 demonstrated the strongest inhibitory effects towards $\alpha$-glucosidase and DPPIV, but not $\alpha$-amylase. This individual fraction should be explored further in future anti-diabetic studies, but its possible cytotoxic effects must be taken into account when designing future experiments. It is again important to emphasise here that F1-F7 were enriched in certain phenolic compounds as mentioned previously and that their effects might also be due to other compounds besides those described.

The anti-diabetic mechanisms investigated in the present study are only a fraction of what is possible. Hence, it would be important that other possible anti-diabetic mechanisms besides those explored in the present study, such as hormonal response to food and modulation of gut flora activities, be investigated as well (Cuervo et al., 2014; Hanhineva et al., 2010; Moco et al., 2012). As such, further pre-clinical studies which investigate the effects of WSPFE using T2DM animal models such as the Nile rat would be useful to explore other in vivo anti-diabetic mechanisms. Human intervention clinical trials administering different forms of carbohydrates in healthy volunteers, such as starch, disaccharides and glucose, together with WSPFE, such as that done by Kerimi et al. (2019) using oleuropein from olives, would also be useful to confirm the inhibitory effects of WSPFE on carbohydrate-hydrolysing enzymes in vivo. It would also be important to carry out studies on postprandial absorption and bioavailability of WSPFE after human consumption in vivo to determine its potential anti-diabetic effects on other types of functional insulin-sensitive tissues post-absorption, such as liver, muscle and adipose tissues (Sun and Miao, 2020). Nevertheless, although direct measurements have not been done to confirm the bioavailability of WSPFE, various in vivo physiological effects previously observed in animal models and human volunteers as reviewed by Leow et al. (2021a) indicate that WSPFE is bioavailable to exert these health functions.

\section{CONCLUSION}

Our previous studies in Nile rats demonstrated the potential anti-diabetic properties of WSPFE, but the related mechanisms were unknown. The present study indicated that WSPFE samples did not inhibit glucose uptake, as shown through experiments using ex vivo everted mouse intestinal sacs and in vitro Caco-2 cell monolayers. The concentrations of WSPFE samples used in the glucose uptake experiments were only up to $500 \mu \mathrm{g} / \mathrm{mL}$, as the $\mathrm{IC}_{50}$ value of the most cytotoxic WSPFE sample against Caco-2 cells, F3, was $544 \pm 48 \mu \mathrm{g} / \mathrm{mL}$. Further experiments on $\alpha$-glucosidase, $\alpha$-amylase and DPPIV enzymes showed that, WSPFE EAF which contained all seven individual WSPFE fractions, consistently had stronger inhibitory effects as compared to SD WSPFE and FD WSPFE. SD WSPFE had better $\alpha$-amylase inhibitory effects than FD WSPFE. In terms of individual fractions, F2 demonstrated the strongest inhibitory effects against $\alpha$-glucosidase and DPPIV. Future studies to investigate the effects of these WSPFE samples on carbohydrate digestion and postprandial hyperglycaemia are thus warranted.

\section{ACKNOWLEDGEMENT}

The authors thank the Director-General of MPOB for permission to publish this article. We also thank the support staff from MPOB who provided technical assistance in various parts of the study, namely Mohamad Daniel Noorazmi for technical assistance in preparing liquid WSPFE, as well as Wan Saridah Wan Omar and Jabariah Md Ali for technical assistance in preparing FD WSPFE and the WSPFE fractions, in addition to carrying out the in vitro enzymatic assays. Special thanks to Chang Wooi Kai for technical assistance in maintaining the Caco-2 cells. This research was funded by MPOB and the Eleventh Malaysia Plan (RMK-11) PROFENOLIS (2011101805) budget.

\section{REFERENCES}

AAT Bioquest (2019). Quest Graph ${ }^{\mathrm{TM}} \mathrm{IC}_{50}$ calculator. https: / / www.aatbio.com/tools/ic50-calculator. 18 June 2021.

Abascal, K; Ganora, L and Yarnell, E (2005). The effect of freeze-drying and its implications for botanical medicine: A review. Phytother. Res., 19(8): 655-660. DOI: 10.1002 / ptr.1651.

Ablat, A; Halabi, M F; Mohamad, J; Hasnan, M H H; Hazni, H; Teh, S H; Shilpi, J A; Mohamed, $\mathrm{Z}$ and Awang, K (2017). Antidiabetic effects of 
Brucea javanica seeds in type 2 diabetic rats. BMC Complement. Altern. Med., 17(1): 94. DOI: 10.1186/ s12906-017-1610-x.

Abotaleb, M; Liskova, A; Kubatka, P and Busselberg, D (2020). Therapeutic potential of plant phenolic acids in the treatment of cancer. Biomolecules, 10(2): 221. DOI: $10.3390 /$ biom 10020221 .

Adefegha, S A; Oboh, G; Ejakpovi, I I and Oyeleye, S I (2015). Antioxidant and antidiabetic effects of gallic and protocatechuic acids: A structure-function perspective. Comp. Clin. Pathol., 24: 1579-1585. DOI: 10.1007/ s00580-015-2119-7.

Alam, M A; Al-Jenoobi, F I and Al-Mohizea, A M (2012). Everted gut sac model as a tool in pharmaceutical research: Limitations and applications. J. Pharm. Pharmacol., 64(3): 326-336. DOI: $10.1111 /$ j.2042-7158.2011.01391.x.

Alzaid, F; Cheung, H M; Preedy, V R and Sharp, P A (2013). Regulation of glucose transporter expression in human intestinal Caco-2 cells following exposure to an anthocyanin-rich berry extract. PLOS ONE, 8(11): e78932. DOI: 10.1371/journal.pone.0078932.

Anantharaju, P G; Gowda, P C; Vimalambike, M G and Madhunapantula, S V (2016). An overview on the role of dietary phenolics for the treatment of cancers. Nutr. J., 15(1): 99. DOI: 10.1186/s12937-0160217-2.

Apostolidis, E and Lee, C M (2010). In vitro potential of Ascophyllum nodosum phenolic antioxidantmediated $\alpha$-glucosidase and $\alpha$-amylase inhibition. J. Food Sci., 75(3): H97-H102. DOI: 10.1111/j.17503841.2010.01544.x.

Bahadoran, Z; Mirmiran, P and Azizi, F (2013). Dietary polyphenols as potential nutraceuticals in management of diabetes: A review. J. Diabetes Metab. Disord., 12(1): 43. DOI: 10.1186/2251-6581-12-43.

Bergman, A; Ebel, D; Liu, F; Stone, J; Wang, A; Zeng, W; Chen, L; Dilzer, S; Lasseter, K; Herman, G; Wagner, J and Krishna, R (2007). Absolute bioavailability of sitagliptin, an oral dipeptidyl peptidase-4 inhibitor, in healthy volunteers. Biopharm. Drug Dispos., 28(6): 315-322. DOI: 10.1002 / bdd.560.

Bolsinger, J; Pronczuk, A; Sambanthamurthi, R and Hayes, K C (2014). Anti-diabetic effects of palm fruit juice in the Nile rat (Arvicanthis niloticus). J. Nutr. Sci., 3: e5. DOI: 10.1017 /jns.2014.3.

Chatterjee, S; Khunti, K and Davies, M J (2017). Type 2 diabetes. Lancet, 389(10085): 2239-2251. DOI: 10.1016/S0140-6736(17)30058-2.
Chen, H; Yao, K; Nadas, J; Bode, A M; Malakhova, M; Oi, N; Li, H; Lubet, R A and Dong, Z (2012). Prediction of molecular targets of cancer preventing flavonoid compounds using computational methods. PLoS ONE, 7(5): e38261. DOI: 10.1371/ journal.pone.0038261.

Chen, N;Gao,HX;He, Q; Yu, ZLand Zeng,WC(2020). Interaction and action mechanism of starch with different phenolic compounds. Int. J. Food Sci. Nutr., 71(6): 726-737. DOI: 10.1080/09637486.2020.1722074.

Cuervo, A; Valdes, L; Salazar, N; De Los ReyesGavilan, C G; Ruas-Madiedo, P; Gueimonde, M and Gonzalez, S (2014). Pilot study of diet and microbiota: Interactive associations of fibers and polyphenols with human intestinal bacteria. J. Agric. Food Chem., 62(23): 5330-5336. DOI: $10.1021 /$ jf501546a.

Derosa, G and Maffioli, P (2012). Efficacy and safety profile evaluation of acarbose alone and in association with other antidiabetic drugs: A systematic review. Clin. Ther., 34(6): 1221-1236. DOI: 10.1016/j.clinthera.2012.04.012.

Ehrenkranz, J R L; Lewis, N G; Kahn, C R and Roth, J (2005). Phlorizin: A review. Diabetes Metab. Res. Rev., 21(1): 31-38. DOI: 10.1002/ dmrr.532.

Fan, J; Johnson, M H; Lila, M A; Yousef, G and De Mejia, E G (2013). Berry and citrus phenolic compounds inhibit dipeptidyl peptidase IV: Implications in diabetes management. Evid. Based Complement. Alternat. Med., 2013: 479505. DOI: $10.1155 / 2013$ / 479505.

Farrell, T L; Ellam, S L; Forrelli, T and Williamson, G (2013). Attenuation of glucose transport across Caco-2 cell monolayers by a polyphenol-rich herbal extract: Interactions with SGLT1 and GLUT2 transporters. BioFactors, 39(4): 448-456. DOI: 10.1002 / biof.1090.

Ferreres, F; Andrade, C; Gomes, N G M; Andrade, P B; Gil-Izquierdo, A; Pereira, D M; Suksungworn, R; Duangsrisai, S; Videira, R A and Valentao, P (2021). Valorisation of kitul, an overlooked food plant: Phenolic profiling of fruits and inflorescences and assessment of their effects on diabetes-related targets. Food Chem., 342: 128323. DOI: 10.1016/j. foodchem.2020.128323.

Gomes, W F; Franca, F R M; Denadai, M; Andrade, J K S; Da Silva Oliveira, E M; De Brito, E S; Rodrigues, $S$ and Narain, N (2018). Effect of freeze- and spraydrying on physico-chemical characteristics, phenolic compounds and antioxidant activity of papaya pulp. J. Food Sci. Technol., 55(6): 2095-2102. DOI: 10.1007 / s13197-018-3124-z. 
Hamilton, K L and Butt, A G (2013). Glucose transport into everted sacs of the small intestine of mice. Adv. Physiol. Educ., 37(4): 415-426. DOI: 10.1152/ advan.00017.2013.

Hanhineva, K; Torronen, R; Bondia-Pons, I; Pekkinen, J; Kolehmainen, M; Mykkanen, $\mathrm{H}$ and Poutanen, K (2010). Impact of dietary polyphenols on carbohydrate metabolism. Int. J. Mol. Sci., 11(4): 1365-1402. DOI: 10.3390/ijms11041365.

Holst, J J (2019). The incretin system in healthy humans: The role of GIP and GLP-1. Metabolism, 96: 46-55. DOI: 10.1016/j.metabol.2019.04.014.

Horszwald, A; Julien, H and Andlauer, W (2013). Characterisation of Aronia powders obtained by different drying processes. Food Chem., 141(3): 28582863. DOI: 10.1016/j.foodchem.2013.05.103.

Huang, P K; Lin, S R; Chang, C H; Tsai, M J; Lee, D N and Weng, C F (2019). Natural phenolic compounds potentiate hypoglycemia via inhibition of dipeptidyl peptidase IV. Sci. Rep., 9(1): 15585. DOI: 10.1038/ s41598-019-52088-7.

Hubatsch, I; Ragnarsson, E G and Artursson, P (2007). Determination of drug permeability and prediction of drug absorption in Caco-2 monolayers. Nat. Protoc., 2(9): 2111-2119. DOI: 10.1038 / nprot.2007.303.

Johnston, K; Sharp, P; Clifford, M and Morgan, L (2005). Dietary polyphenols decrease glucose uptake by human intestinal Caco-2 cells. FEBS Lett., 579(7): 1653-1657. DOI: 10.1016/j.febslet.2004.12.099.

Kakkar, S and Bais, S (2014). A review on protocatechuic acid and its pharmacological potential. ISRN Pharmacol., 2014: 952943. DOI: $10.1155 / 2014 / 952943$.

Kerimi, A; Nyambe-Silavwe, H; Pyner, A; Oladele, E; Gauer, J S; Stevens, Y and Williamson, G (2019). Nutritional implications of olives and sugar: Attenuation of post-prandial glucose spikes in healthy volunteers by inhibition of sucrose hydrolysis and glucose transport by oleuropein. Eur. J. Nutr., 58(3): 1315-1330. DOI: 10.1007 / s00394-0181662-9.

Kim, B R; Kim, H Y; Choi, I; Kim, J B; Jin, CH and Han, A R (2018). DPP-IV inhibitory potentials of flavonol glycosides isolated from the seeds of Lens culinaris: In vitro and molecular docking analyses. Molecules, 23(8): 1998. DOI: 10.3390 / molecules23081998.

Kim, D; Wang, L; Beconi, M; Eiermann, G J; Fisher, M H; He, H; Hickey, G J; Kowalchick, J E; Leiting, B; Lyons, K; Marsilio, F; Mccann, M E; Patel, R A; Petrov,
A; Scapin, G; Patel, S B; Roy, R S; Wu, J K; Wyvratt, M J; Zhang, B B; Zhu, L; Thornberry, N A and Weber, A E (2005). (2R)-4-oxo-4-[3-(trifluoromethyl)-5,6dihydro[1,2,4]triazolo[4,3-a]pyrazin-7(8H)- yl]-1(2,4,5-trifluorophenyl)butan-2-amine: A potent, orally active dipeptidyl peptidase IV inhibitor for the treatment of type 2 diabetes. J. Med. Chem., 48(1): 141-151. DOI: 10.1021 /jm0493156.

Kim, S Y; Ryu, J S; Li, H; Park, W J; Yun, H Y; Baek, K J; Kwon, N S; Sohn, U D and Kim, D S (2010). UVBactivated indole-3-acetic acid induces apoptosis of PC-3 prostate cancer cells. Anticancer Res., 30(11): 4607-4612.

Leow, S S; Fairus, S and Sambanthamurthi, R (2021a). Water-Soluble Palm Fruit Extract: Composition, biological properties, and molecular mechanisms for health and non-health applications. Crit. Rev. Food Sci. Nutr. DOI: 10.1080/10408398.2021.1939648.

Leow, S S; Fairus, S and Sambanthamurthi, R (2021b). Inhibition of cholinesterases by Water-Soluble Palm Fruit Extract. J. Oil Palm Res. DOI: 10.21894/ jopr.2021.0028.

Li, Z; Zhao, L; Yu, L and Yang, J (2019). Head-tohead comparison of the hypoglycemic efficacy and safety between dipeptidyl peptidase- 4 inhibitors and $\alpha$-glucosidase inhibitors in patients with type 2 diabetes mellitus: A meta-analysis of randomized controlled trials. Front. Pharmacol., 10: 777. DOI: 10.3389/ fphar.2019.00777.

Ling, J; Cheng, P; Ge, L; Zhang, D H; Shi, A C; Tian, J H; Chen, Y J; Li, X X; Zhang, J Y and Yang, K H (2019). The efficacy and safety of dipeptidyl peptidase- 4 inhibitors for type 2 diabetes: A Bayesian network meta-analysis of 58 randomized controlled trials. Acta Diabetol., 56(3): 249-272. DOI: $10.1007 /$ s00592018-1222-z.

Luz-Madrigal, A; Grajales-Esquivel, E and Del Rio-Tsonis, K (2015). Electroporation of embryonic chick eyes. Bio. Protoc., 5(12): e1498. DOI: 10.21769 / BioProtoc. 1498.

Lyssenko, V; Jonsson, A; Almgren, P; Pulizzi, N; Isomaa, B; Tuomi, T; Berglund, G; Altshuler, D; Nilsson, P and Groop, L (2008). Clinical risk factors, DNA variants, and the development of type 2 diabetes. N. Engl. J. Med., 359(21): 2220-2232. DOI: 10.1056/ NEJMoa0801869.

Manzano, S and Williamson, G (2010). Polyphenols and phenolic acids from strawberry and apple decrease glucose uptake and transport by human intestinal Caco-2 cells. Mol. Nutr. Food Res., 54(12): 1773-1780. DOI: 10.1002/mnfr.201000019. 
Mary, P L and Rao, J P (2002). Phenol red inhibits uptake of phosphate by the everted gut sacs of mice. Kobe J. Med. Sci., 48(1-2): 59-62.

Moco, S; Martin, F P J and Rezzi, S (2012). Metabolomics view on gut microbiome modulation by polyphenol-rich foods. J. Proteome Res., 11(10): 4781-4790. DOI: 10.1021 / pr300581s.

Nauck, M A and Meier, J J (2018). Incretin hormones: Their role in health and disease. Diabetes Obes. Metab., 20 Suppl 1: 5-21. DOI: 10.1111/dom.13129.

Neubig, R R; Spedding, M; Kenakin, $\mathrm{T}$ and Christopoulos, A (2003). International Union of Pharmacology Committee on receptor nomenclature and drug classification. XXXVIII. Update on terms and symbols in quantitative pharmacology. Pharmacol. Rev., 55(4): 597-606. DOI: 10.1124/ pr.55.4.4.

Nguyen, P T M; Ngo, Q V; Nguyen, M T H; Maccarone, A T and Pyne, S G (2020a). $\alpha$-Glucosidase inhibitory activity of the extracts and major phytochemical components of Smilax glabra Roxb. Nat. Prod. J., 10(1): 26-32. DOI: 10.2174 / 2210315509666190124111435.

Nguyen, P T M; Ngo, Q V; Nguyen, M T H; Quach, L T and Pyne, S G (2020b). Hypoglycemic activity of the ethyl acetate extract from Smilax glabra Roxb in mice: Biochemical and histopathological studies. Iran. J. Basic Med. Sci., 23(12): 1558-1564. DOI: 10.22038/ijbms.2020.46658.10763.

Nyambe-Silavwe, H and Williamson, G (2018). Chlorogenic and phenolic acids are only very weak inhibitors of human salivary $\alpha$-amylase and rat intestinal maltase activities. Food Res. Int., 113: 452455. DOI: $10.1016 /$ j.foodres.2018.07.038.

Oboh, G; Ogunsuyi, O B; Ogunbadejo, M D and Adefegha, S A (2016). Influence of gallic acid on $\alpha$-amylase and $\alpha$-glucosidase inhibitory properties of acarbose. J. Food Drug Anal., 24(3): 627-634. DOI: 10.1016/j.jfda.2016.03.003.

Olatunji, O J; Chen, H and Zhou, Y (2017). Effect of the polyphenol rich ethyl acetate fraction from the leaves of Lycium chinense Mill. on oxidative stress, dyslipidemia, and diabetes mellitus in streptozotocin-nicotinamide induced diabetic rats. Chem. Biodiversity, 14(10): e1700277. DOI: 10.1002/ cbdv.201700277.

Ooi, D J; Chan, K W; Sarega, N; Alitheen, N B; Ithnin, $\mathrm{H}$ and Ismail, $\mathrm{M}$ (2016). Bioprospecting the curculigoside-cinnamic acid-rich fraction from Molineria latifolia rhizome as a potential antioxidant therapeutic agent. Molecules, 21(6): 682. DOI: 10.3390 / molecules21060682.

Ooi, D J; Adamu, H A; Imam, M U; Ithnin, $\mathrm{H}$ and Ismail, M (2018). Polyphenol-rich ethyl acetate fraction isolated from Molineria latifolia ameliorates insulin resistance in experimental diabetic rats via IRS1 / AKT activation. Biomed. Pharmacother., 98: 125133. DOI: 10.1016/j.biopha.2017.12.002.

Orhan, N; Aslan, M; Pekcan, M; Orhan, D D; Bedir, E and Ergun, F (2012). Identification of hypoglycaemic compounds from berries of Juniperus oxycedrus subsp. oxycedrus through bioactivity guided isolation technique. J. Ethnopharmacol., 139(1): 110-118. DOI: 10.1016/j.jep.2011.10.027.

Pham, A T; Malterud, K E; Paulsen, B S; Diallo, D and Wangensteen, H (2014). $\alpha$-Glucosidase inhibition, 15-lipoxygenase inhibition, and brine shrimp toxicity of extracts and isolated compounds from Terminalia macroptera leaves. Pharm. Biol., 52(9): 1166-1169. DOI: 10.3109/13880209.2014.880486.

Rasouli, H; Hosseini-Ghazvini, S M; Adibi, $\mathrm{H}$ and Khodarahmi, R (2017). Differential $\alpha$-amylase $/ \alpha$ glucosidase inhibitory activities of plant-derived phenolic compounds: A virtual screening perspective for the treatment of obesity and diabetes. Food Funct., 8(5): 1942-1954. DOI: 10.1039 / c7fo00220c.

Rosa, L S; Silva, N J A; Soares, N C P; Monteiro, M $\mathrm{C}$ and Teodoro, A J (2016). Anticancer properties of phenolic acids in colon cancer - A review. J. Nutr. Food Sci., 6: 468. DOI: 10.4172/2155-9600.1000468.

Rosak, C and Mertes, G (2012). Critical evaluation of the role of acarbose in the treatment of diabetes: Patient considerations. Diabetes Metab. Syndr. Obes., 5: 357-367. DOI: 10.2147/DMSO.S28340.

Sambandan, T G; Rha, C K; Sambanthamurthi, R; Sinskey, A J; Tan, Y A; Sundram, K and Wahid, M B (2011). Compositions comprising shikimic acid obtained from oil palm based materials and method of producing thereof. Malaysian Palm Oil Board. WIPO Patent Application WO 2011/159144.

Sambanthamurthi, R; Tan, Y A and Sundram, K (2008). Treatment of vegetation liquors derived from oil-bearing fruit. Malaysian Palm Oil Board. United States Patent US 7387802 B2.

Sambanthamurthi, R; Tan, Y A; Sundram, K; Abeywardena, M; Sambandan, T G; Rha, C; Sinskey, A J; Subramaniam, K; Leow, S S; Hayes, K C and Wahid, M B (2011a). Oil palm vegetation liquor: A new source of phenolic bioactives. Br. J. Nutr., 106(11): 1655-1663. DOI: 10.1017/S0007114511002121. 
Sambanthamurthi, R; Tan, Y A; Sundram, K; Hayes, K C; Abeywardena, M; Leow, S S; Sekaran, S D; Sambandan, T G; Rha, C; Sinskey, A J; Subramaniam, K; Fairus, S and Wahid, M B (2011b). Positive outcomes of oil palm phenolics on degenerative diseases in animal models. Br. J. Nutr., 106(11): 16641675. DOI: $10.1017 /$ S0007114511002133.

Sambanthamurthi, R; Tan, Y A; Omar, W S W; Ali, J M; Sambandan, T G; Yang, M F; Rha, C K and Sinskey, A J (2014). Isolation of a novel bioactive compound obtained from oil palm base materials. Malaysian Palm Oil Board. WIPO Patent Application WO 2014/209100.

Sambuy, Y; De Angelis, I; Ranaldi, G; Scarino, M L; Stammati, A and Zucco, F (2005). The Caco-2 cell line as a model of the intestinal barrier: Influence of cell and culture-related factors on Caco-2 cell functional characteristics. Cell Biol. Toxicol., 21(1): 1-26. DOI: 10.1007/s10565-005-0085-6.

Santo, E F D E; Lima, L K F D; Torres, A P C; Oliveira, G D and Ponsano, E H G (2013). Comparison between freeze and spray drying to obtain powder Rubrivivax gelatinosus biomass. Food Sci. Technol., 33: 47-51. DOI: 10.1590/S0101-20612013005000008.

Sarian, M N; Ahmed, Q U; Mat So'ad, S Z; Alhassan, A M; Murugesu, S; Perumal, V; Syed Mohamad, S N A; Khatib, A and Latip, J (2017). Antioxidant and antidiabetic effects of flavonoids: A structureactivity relationship based study. Biomed. Res. Int. 2017: 8386065. DOI: 10.1155/2017 / 8386065.

Scheepers, A; Joost, H G and Schurmann, A (2004). The glucose transporter families SGLT and GLUT: Molecular basis of normal and aberrant function. JPEN J. Parenter. Enteral Nutr., 28(5): 364-371. DOI: 10.1177 / 0148607104028005364.

Seidel, C; Schnekenburger, M; Dicato, M and Diederich, M (2014). Antiproliferative and proapoptotic activities of 4-hydroxybenzoic acid-based inhibitors of histone deacetylases. Cancer Lett., 343(1): 134-146. DOI: 10.1016/j. canlet.2013.09.026.

Sekaran, S D; Leow, S S; Abobaker, N; Tee, K K; Sundram, K; Sambanthamurthi, R and Wahid, M B (2010). Effects of oil palm phenolics on tumor cells in vitro and in vivo. Afri. J. Food Sci., 4(8): 495-502. DOI: 10.5897 / AJFS.9000113.

Singh, A K; Jatwa, R; Purohit, A and Ram, H (2017). Synthetic and phytocompounds based dipeptidyl peptidase-IV (DPP-IV) inhibitors for therapeutics of diabetes. J. Asian Nat. Prod. Res., 19(10): 1036-1045. DOI: $10.1080 / 10286020.2017 .1307183$.
Sirisena, S; Ng, K and Aljouni, S (2016). Antioxidant activities and inhibitory effects of free and bound polyphenols from date (Phoenix dactylifera L.) seeds on starch digestive enzymes. Int. J. Food Stud., 5: 212223. DOI: 10.7455 /ijfs/5.2.2016.a9.

Sousa, B A and Correia, R T P(2012). Phenolic content, antioxidant activity and antiamylolytic activity of extracts obtained from bioprocessed pineapple and guava wastes. Braz. J. Chem. Eng., 29(1): 25-30. DOI: 10.1590/S0104-66322012000100003.

Sravanthi, T; Sajitha Lulu, S; Vino, S; Jayasri, M A; Mohanapriya, A and Manju, S L (2017). Synthesis, docking, and evaluation of novel thiazoles for potent antidiabetic activity. Med. Chem. Res., 26: 1306-1315. DOI: 10.1007 / s00044-017-1851-8.

Striegel, L; Kang, B; Pilkenton, S J; Rychlik, M and Apostolidis, E (2015). Effect of black tea and black tea pomace polyphenols on $\alpha$-glucosidase and $\alpha$-amylase inhibition, relevant to type 2 diabetes prevention. Front. Nutr., 2: 3. DOI: 10.3389/ fnut.2015.00003.

Sun, L and Miao, M (2020). Dietary polyphenols modulate starch digestion and glycaemic level: A review. Crit. Rev. Food Sci. Nutr., 60(4): 541-555. DOI: 10.1080/10408398.2018.1544883.

Tanaka, T; Tanaka, T and Tanaka, M (2011). Potential cancer chemopreventive activity of protocatechuic acid. J. Exp. Clin. Med., 3(1): 27-33. DOI: 10.1016/j. jecm.2010.12.005.

Verma, A and Singh, S V (2015). Spray drying of fruit and vegetable juices - A review. Crit. Rev. Food Sci. Nutr., 55(5): 701-719. DOI: 10.1080/10408398.2012. 672939 .

Wardman, P (2002). Indole-3-acetic acids and horseradish peroxidase: A new prodrug/ enzyme combination for targeted cancer therapy. Curr. Pharm. Des., 8(15): 1363-1374. DOI: $10.2174 / 1381612023394610$.

Xu, H; Leng, X; Wang, M and Zhang, G (2012). Glucose measurement in the presence of tea polyphenols. Food Anal. Methods, 5: 1027-1032. DOI: 10.1007 / s12161-011-9335-9.

Yee, H S and Fong, N T (1996). A review of the safety and efficacy of acarbose in diabetes mellitus. Pharmacotherapy, 16(5): 792-805. DOI: 10.1002 /j.18759114.1996.tb02997.x.

Zeng, X; Wang, Y; Qiu, Q; Jiang, C; Jing, Y; Qiu, G and He, $X$ (2012). Bioactive phenolics from the fruits of Livistona chinensis. Fitoterapia, 83(1): 104-109. DOI: 10.1016/j.fitote.2011.09.020. 
Zhu, Y; Zhao, J; Luo, L; Gao, Y; Bao, H; Li, P and Zhang, $\mathrm{H}$ (2021). Research progress of indole compounds with potential antidiabetic activity. Eur. J. Med. Chem., 223: 113665. DOI: 10.1016/j.ejmech.2021.113665. 